\title{
Aerodynamic Analyses and Database Development for Lift-Off/Transition and First Stage Ascent of the Ares I A106 Vehicle
}

\author{
Bandu N. Pamadi* \\ NASA Langley Research Center, Hampton, VA 23681 \\ Jing Pei ${ }^{\dagger}$ \\ NASA Langley Research Center, Hampton, VA 23681 \\ Peter.F. Covell ${ }^{\ddagger}$ \\ NASA Langley Research Center, Hampton, VA 23681 \\ Noah M. Favaregh ${ }^{\S}$ \\ Analytical Mechanics Associates, Hampton, VA \\ Clyde R. Gumbert ${ }^{* *}$ \\ NASA Langley Research Center, Hampton, VA 23681 \\ Jeremy L. Hanke ${ }^{\dagger \dagger}$ \\ NASA Langley Research Center, Hampton, VA 23681
}

\begin{abstract}
NASA Langley Research Center, in partnership with NASA Marshall Space Flight Center and NASA Ames Research Center, was involved in the aerodynamic analyses, testing, and database development for the Ares I A106 crew launch vehicle in support of the Ares Design and Analysis Cycle. This paper discusses the development of lift-off/transition and ascent databases. The lift-off/transition database was developed using data from tests on a $1.75 \%$ scale model of the A106 configuration in the NASA Langley 14x22 Subsonic Wind Tunnel. The power-off ascent database was developed using test data on a 1\% A106 scale model from two different facilities, the Boeing Polysonic Wind Tunnel and the NASA Langley Unitary Plan Wind Tunnel. The ascent database was adjusted for differences in wind tunnel and flight Reynolds numbers using USM3D CFD code. The aerodynamic jet interaction effects due to first stage roll control system were modeled using USM3D and OVERFLOW CFD codes.
\end{abstract}

\footnotetext{
*Ares Aero Database Manager, Langley Ares Project Office; Senior Aerospace Engineer, Vehicle Analysis Branch, Systems Analysis and Concepts Directorate. Associate Fellow AIAA, Bandu.N.Pamadi@nasa.gov

${ }^{\dagger}$ Engineer, Vehicle Analysis Branch, Systems Analysis and Concepts Directorate, Member AIAA, Jing.Pei-

1@nasa.gov.

${ }^{*}$ Chief Engineer, Langley Ares Project Office; Senior Engineer,Vehicle Analysis Branch, System Analysis and Concepts Directorate, Associate Fellow AIAA, Peter.F.Covell@nasa.gov.

${ }^{\S}$ Engineer, Member AIAA, Noah.M.Favaregh@nasa.gov.

${ }^{* *}$ Senior Aerospace Engineer, Vehicle Analysis Branch, System Analysis and Concepts Directorate, Clyde.R.Cumbert@nasa.gov.

${ }_{\dagger}^{\dagger}$ Engineer, Configuration Aerodynamics Branch, Research and Technology Directorate, jeremy.1.hanke@nasa.gov. 


\section{Nomenclature}

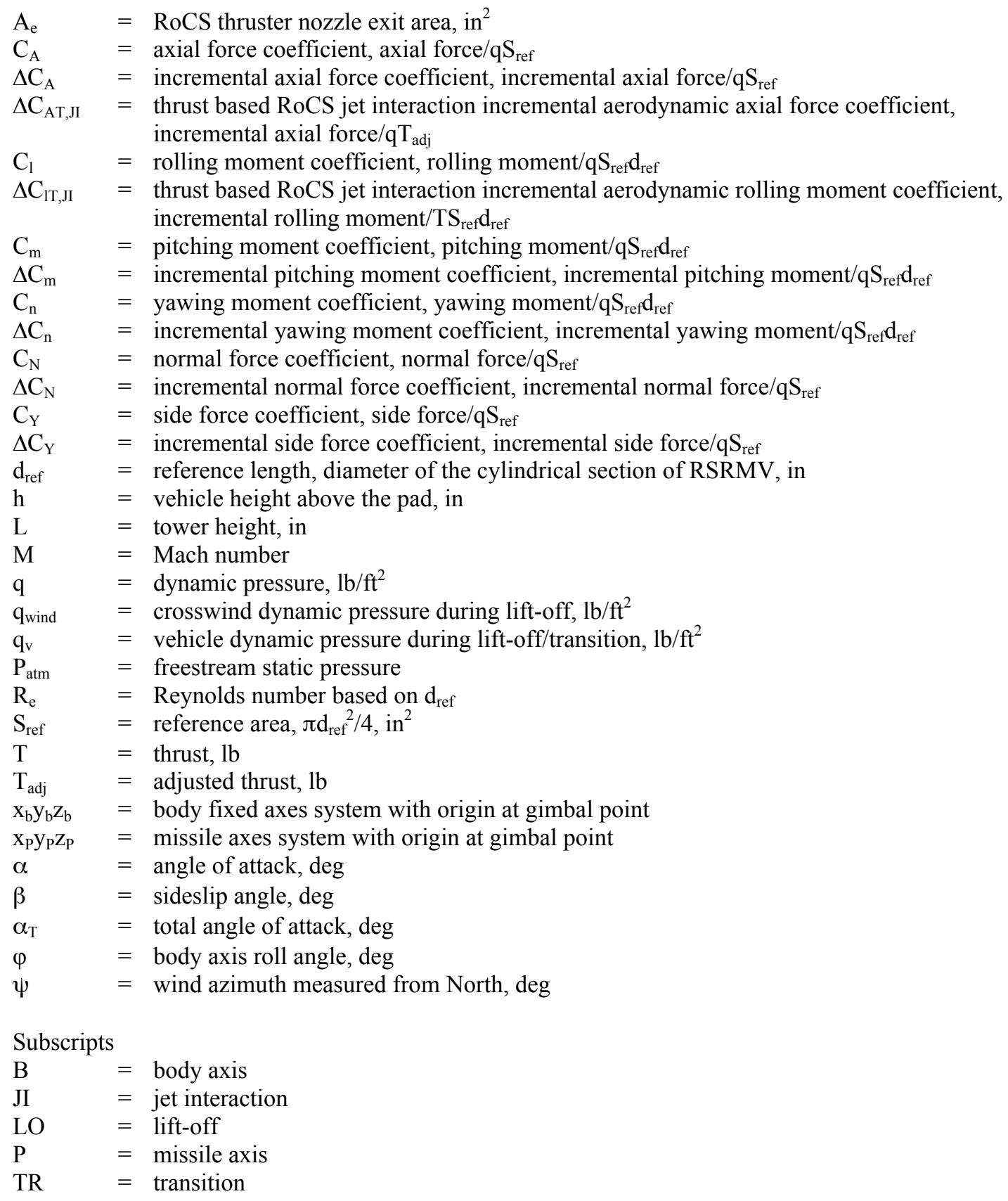

Acronyms:

$\begin{array}{ll}\text { ADAC } & =\text { Ares Design and Analysis Cycle } \\ \text { AEDC } & =\text { Arnold Engineering and Development Corporation } \\ \mathrm{BDM} & =\text { booster deceleration motor } \\ \mathrm{BSM} & =\text { booster separation motor } \\ \mathrm{BTM} & =\text { booster tumble motor } \\ \mathrm{CLV} & =\text { crew launch vehicle } \\ \mathrm{CEV} & =\text { crew exploration vehicle } \\ \mathrm{DOF} & =\text { degree-of-freedom } \\ \mathrm{CM} & =\text { command module }\end{array}$




$\begin{array}{ll}\text { ESM } & =\text { encapsulated service module } \\ \text { GNC } & =\text { guidance, navigation and control } \\ \text { JI } & =\text { jet interaction } \\ \text { ISS } & =\text { International Space Station } \\ \text { LAS } & =\text { launch abort system } \\ \text { LEO } & =\text { low earth orbit } \\ \text { OML } & =\text { outer mold line } \\ \text { PSWT } & =\text { Poly Sonic Wind Tunnel (Boeing) } \\ \text { ReCS } & =\text { reaction control system (upper stage) } \\ \text { RoCS } & \text { roll control system (first stage) } \\ \text { RSRMV } & =\text { redesigned solid rocket motor V (five segments) } \\ \text { SA } & =\text { spacecraft adapter } \\ \text { SM } & =\text { service module } \\ \text { SRB } & =\text { solid rocket booster } \\ \text { SWT } & =\text { subsonic wind tunnel } \\ \text { TD6 } & =\text { dispersed trajectories generated in GNC cycle } 6 \\ \text { TD7 } & =\text { dispersed trajectories generated in GNC cycle } 7 \\ \text { TR5 } & =\text { reference trajectory generated in GNC cycle } 5 \\ \text { TR6 } & =\text { reference trajectory generated in GNC cycle } 6 \\ \text { TR7 } & =\text { reference trajectory generated in GNC cycle } 7 \\ \text { UPWT } & =\text { Unitary Plan Wind Tunnel } \\ \text { USM } & =\text { ullage settling motor }\end{array}$

\section{Introduction}

The Constellation program was a key element of NASA's Vision for Space Exploration ${ }^{1}$. One of the primary elements of that program was the design and development of a crew launch vehicle (CLV) to launch the crew exploration vehicle (CEV) into Low Earth Orbit (LEO). The CLV was later named the Ares I. The Ares design and analyses cycle (ADAC) began in 2006 and the Ares I vehicle configuration gradually evolved with progression of ADAC activity. The preliminary design review of the Ares I was held in September 2008, the critical design review was scheduled for 2011 and Ares I was expected to be operational by 2015. The first developmental test vehicle named Ares I-X was flown successfully on October 28, 2009. However, the constellation program was canceled in October 2010. At that time, the ADAC-3 was in progress and the vehicle configuration was designated as A106. NASA Langley Research Center in partnership with NASA Marshall Space Flight Center and NASA Ames Research Center was involved in aerodynamic characterization and database development activity for A106 configuration. Ref. 2 discusses the development of the database for A106 first stage separation. This paper discusses the development of lift-off/transition and ascent databases for the A106 configuration.

The Ares I is a multistage launch vehicle (Figure 1). The first stage is a five-segment redesigned solid rocket motor (RSRMV), a derivative of the Space Shuttle four-segment solid rocket booster and is being developed by ATK under contract with NASA. The second stage vehicle comprises the launch abort system (LAS), the crew module $(\mathrm{CM})$, the service module (SM), the spacecraft adapter (SA), the upper stage propulsion elements such as liquid oxygen (LOX) and hydrogen (H2) tanks; and the J2-X engine. The combination of the LAS, the CM, the SM and the $\mathrm{SA}$, is called the crew exploration vehicle (CEV), which is also known as Orion.

The A106 configuration has 10 booster deceleration motors (BDMs) located at forward location on the aft-skirt

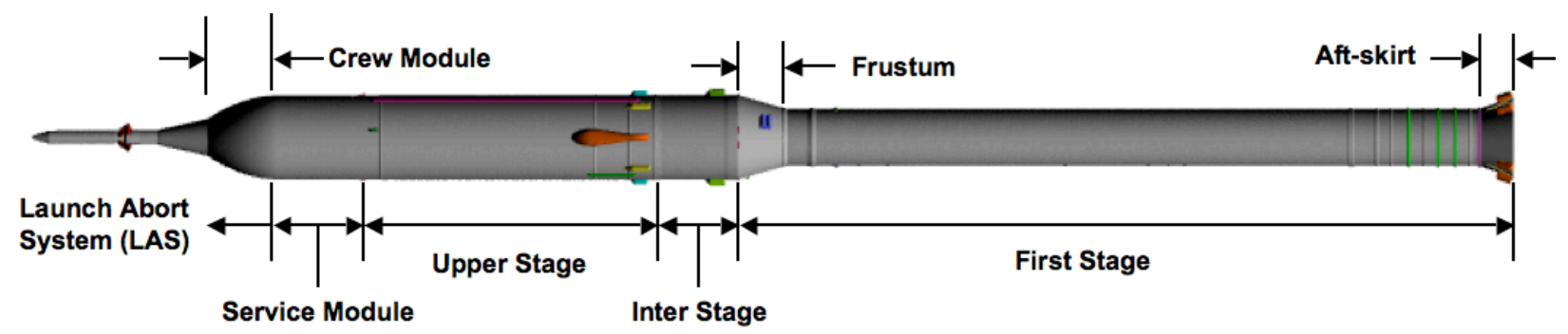

Figure 1. Ares I A106 configuration showing major components.

3

American Institute of Aeronautics and Astronautics 
of the first stage and 4 booster tumble motors (BTMs) contained in 2 pods (2 motors in each pod) on the frustum. Each BDM is the same as the Space Shuttle booster separation motor (BSM) used for SRB separation from the External Tank/Orbiter. The BDMs are used to decelerate the first stage relative to the upper stage to aid axial separation. When the two stages are separated safely, the BTMs fire to put the first stage (with interstage attached) in a tumbling motion to dissipate energy and aid the parachute recovery. The first stage roll control system (RoCS) motors are located on the inter-stage and are used to balance the first stage combined aerodynamic rolling moment and the induced roll torque due to swirl and asymmetrical burning of the RSRMV. The upper stage reaction control motors (ReCS) are used for upper stage roll control subsequent to stage separation. All of the external structures, except the LAS nozzles, are usually referred to as protuberances. The umbilical between the CM and the SM, the liquid hydrogen (LH2) feed-line fairing are two of the prominent protuberances on the A106 configuration. The major components and protuberances of the A106 configuration are shown in Figure 1.

The nominal ascent trajectory (TR7 from GNC cycle 7) for the international space station (ISS) mission is shown in Figure 2. After lift-off/transition, the vehicle makes a gravity turn and follows a non-lifting ascent trajectory up to staging which nominally occurs around Mach 5.7 and an altitude of about 190,000 ft. The first stage recovery proc-

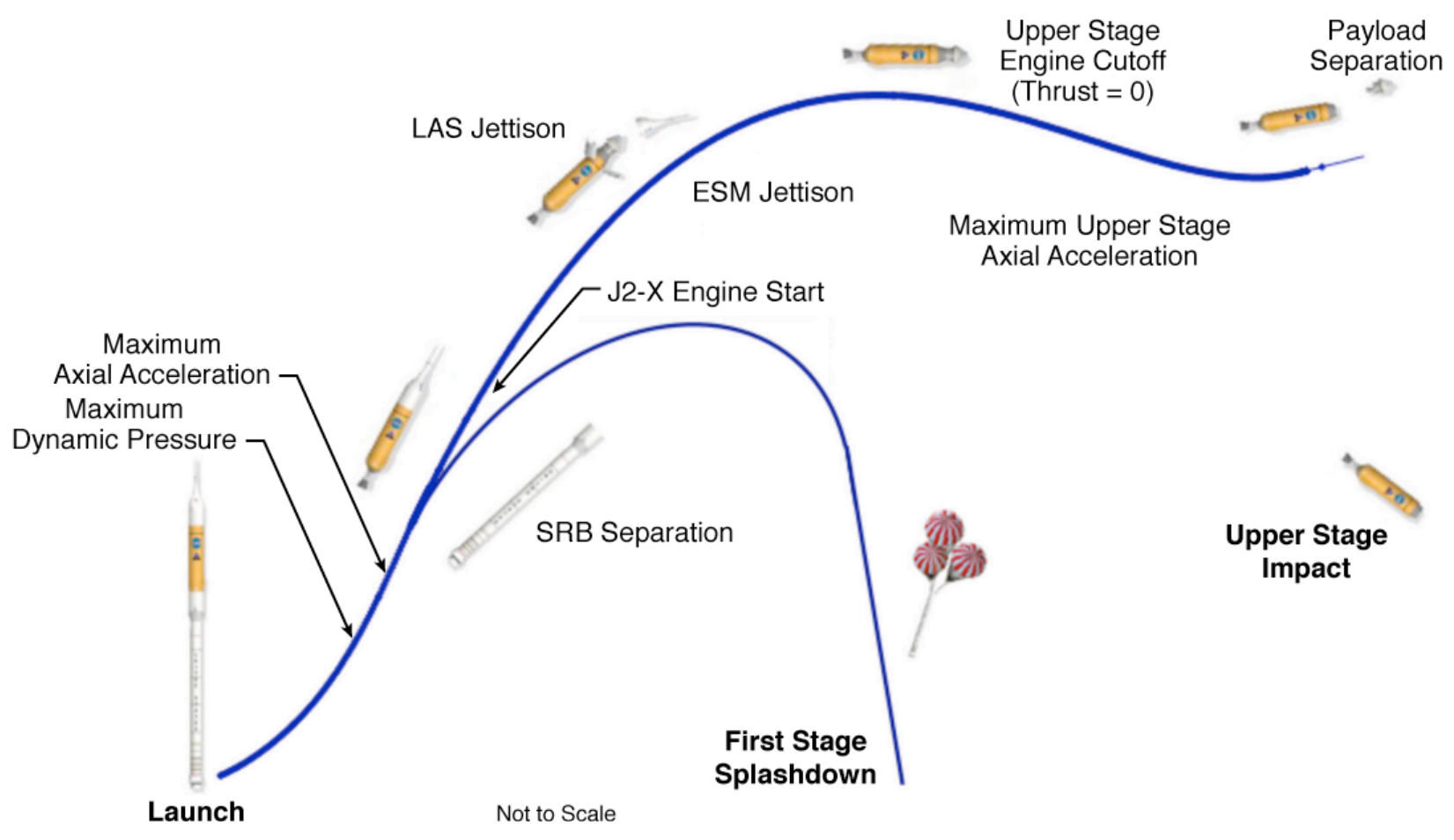

Figure 2: Ares I A106 crew launch vehicle reference Trajectory (TR7).

ess is similar to that of the current Shuttle SRB. The LAS separation occurs at approximately at Mach 6.5 at an altitude of 200,000 ft. Subsequently, the CEV separates from the upper stage (without LAS) and continues in its journey to the ISS. The rest of the upper stage disintegrates during its return to Earth and it is not recovered.

The lift-off/transition database (angle of attack from 90 to 0 degrees) for Apollo-Saturn $\mathrm{V}^{3}$ and Space Shuttle ${ }^{4}$ were developed using wind tunnel data at low angle of attack, ground wind loads wind tunnel data at 90 deg angle of attack, and empirical bridging functions for intermediate angles of attack. Launch tower interference effects for Apollo-Saturn $\mathrm{V}^{3}$ and Space Shuttle ${ }^{4}$ were derived from ground wind loads wind tunnel tests of the vehicle on the launch pad and an empirical model for after lift-off to tower clearance. However, a higher fidelity model with minimal empirical estimates was required for Ares I because preliminary lift-off trajectory simulations indicated the potential for impact of the vehicle with the tower in the presence ground winds up to the required maximum speed. Therefore, the Ares I lift-off/transition database was developed using wind tunnel test data across the entire angle of attack range ( 90 to $0 \mathrm{deg}$ ). The tower interference effects were also derived from wind tunnel tests of the vehicle both on the pad and at various heights relative to the tower. 

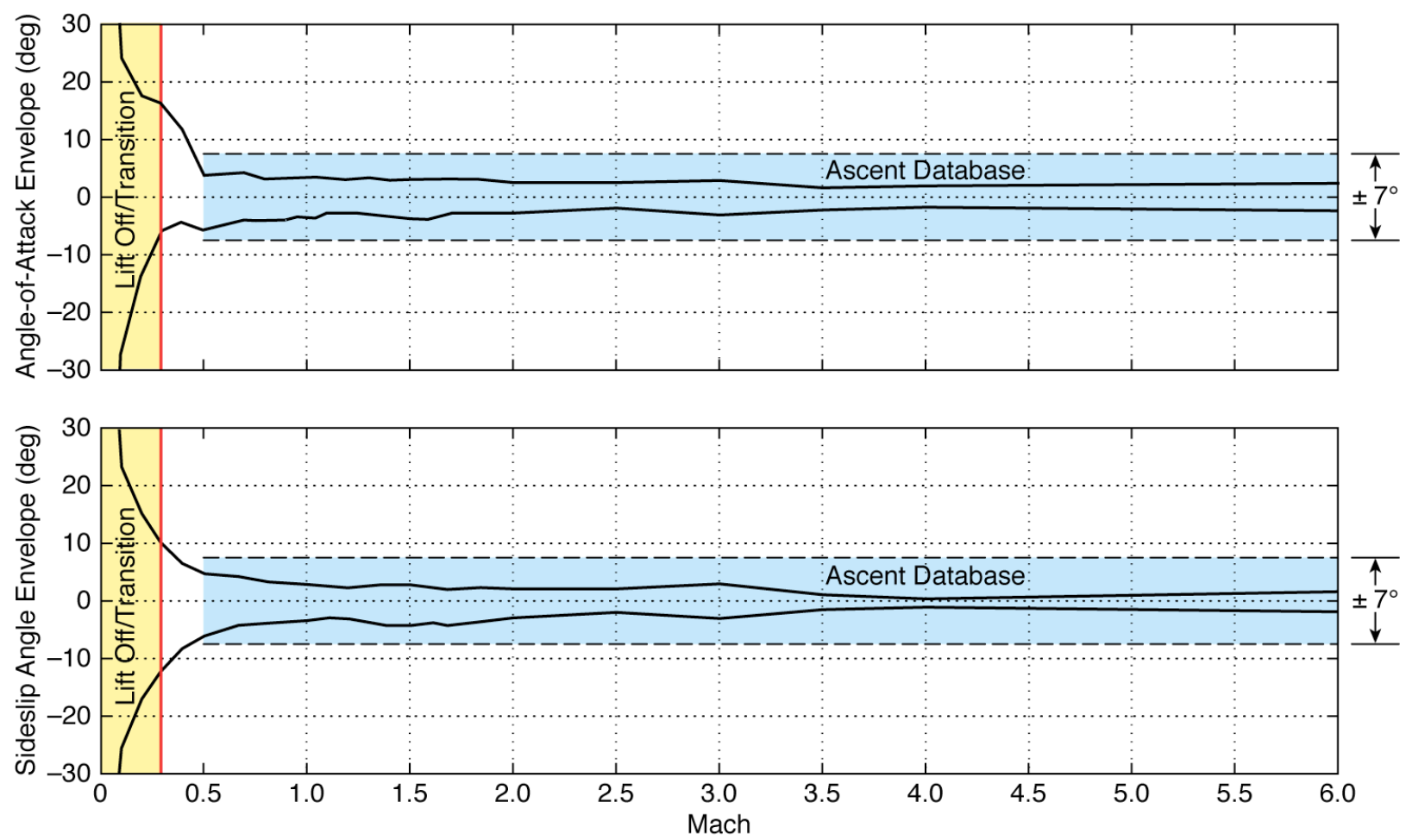

Figure 3: Angle of attack and sideslip envelopes for first stage lift-off/transition and ascent.

In a similar manner as for Saturn $\mathrm{V}^{3}$ and Space Shuttle ${ }^{4}$, the Ares I ascent database was developed using wind tunnel $x$ data. However, special care was needed in these wind tunnel tests. The characterization of aerodynamic rolling moment during first stage ascent had assumed critical importance for Ares I crew launch vehicle because the RoCS system used for balancing the combined thrust induced roll torque and aerodynamic rolling moment was pushed to its limits, particularly in transonic and low supersonic regions when the vehicle encounters high dynamic pressures. Since aerodynamic rolling moment is primarily due to protuberances and is order of magnitude smaller than other forces/moments, specially designed and calibrated strain gage balances were used for these wind tunnel tests. In addition for Ares I, OVERFLOW and USM3D CFD codes were used to estimate the increments for Reynolds number differences between wind tunnel and flight as well as aerodynamic jet interaction effects due to RoCS jet firing.

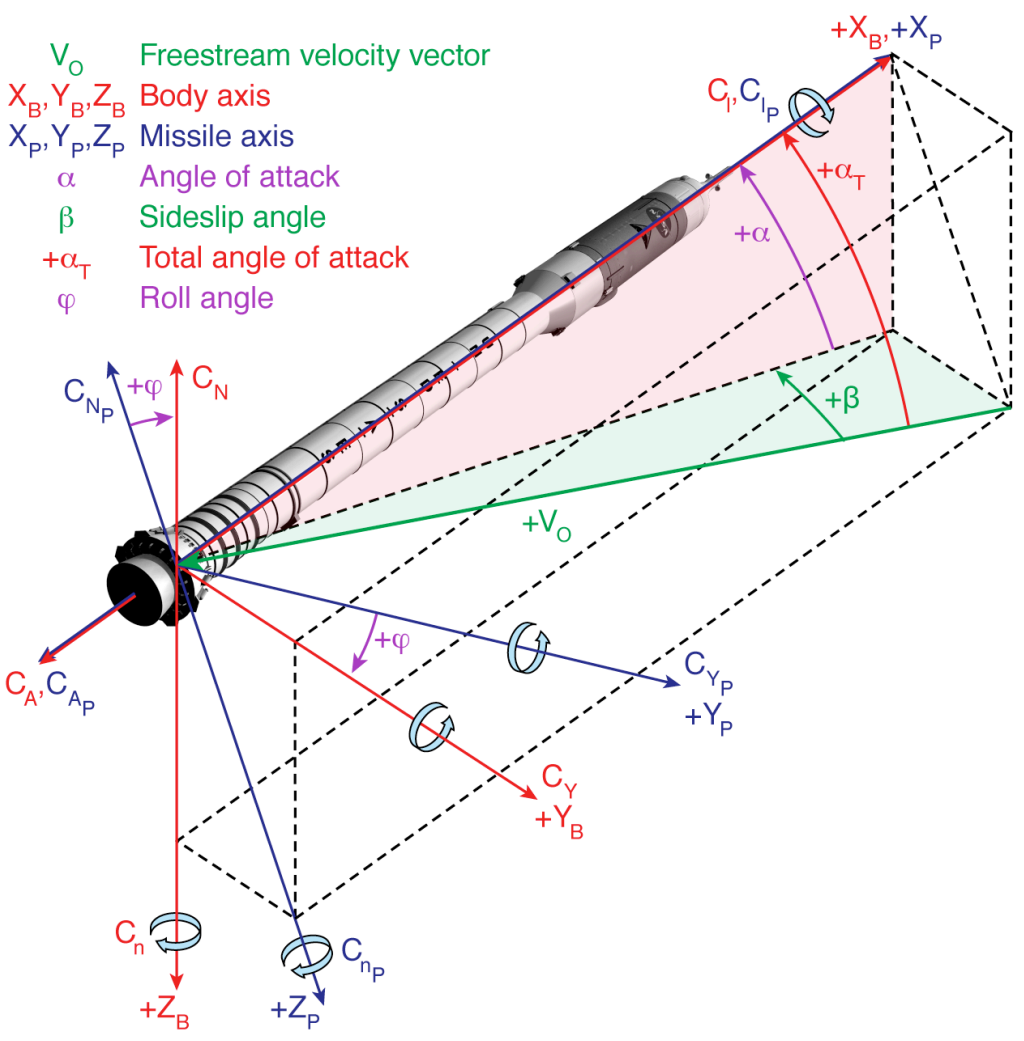

Figure 4. Reference coordinate system.

5

American Institute of Aeronautics and Astronautics 
The angle of attack/sideslip envelopes from TD7 dispersed trajectories along with the ranges of angles of attack and sideslip covered by lift-off/transition database and ascent database are shown in Figure 3. The lift-off/transition database applies for Mach 0 to 0.3 . The lift-off database covers the vehicle on launch pad at various heights with respect to tower. The transition database covers angles of attack/sideslip from -90 to $90 \mathrm{deg}$. The ascent database applies to ascent flight following gravity turn and covers Mach 0.5 to 6.0 and angles of attack/sideslip from -7 to +7 deg. For the Mach 0.3 to 0.5 range, interpolation is to be used. The development of uncertainty and the RSRMV plume effects are not discussed here but are available in the A106 aerodynamic data book. ${ }^{5}$

The reference coordinate system used in the database development is shown in Figure 4. The origin is located at the RSRMV gimbal point.

\section{Wind Tunnel Tests}

\section{A. Lift-Off/Transition Tests}

The lift-off/transition database was developed using the data from Test \#591 conducted in the NASA Langley 14x22 Subsonic Wind Tunnel (SWT) on a 1.75\% scale model of A106 configuration during September 2009. The test data were acquired for two cases, (a) tower-on and (b) tower-off. For tower-on tests, the model was positioned at various heights relative to the tower. To simulate full-scale flow conditions, uniform grit was selected because it generated a tripped flow without causing flow separation. With this grit, nearly identical test data were acquired for dynamic pressure (q) variations from $40 \mathrm{psf}$ to $80 \mathrm{psf}$ so that these runs could be treated as repeat runs. The majority of the test data used in the database development were acquired at dynamic pressures of $40 \mathrm{psf}$ and $80 \mathrm{psf}$. The wind tunnel (WT) tower model geometry was based on the Crew Launch Vehicle Mobile Launcher, Launch Complex 39 Design Criteria (Drawing No. 242MDC00001, December 10, 2008) provided by Kennedy Space Center (KSC). This tower configuration is called as the baseline tower. In addition to the baseline tower, two other tower configurations with different porosity to simulate different levels of blockage due structures not modeled on each level of the tower were also tested. The test data on the baseline tower was used to develop the lift-off database and the data on other two towers were used for uncertainty development ${ }^{5}$.

The entire assembly was mounted on a turntable and rotated 0 to 360 deg to simulate the variation in wind azimuth. Photographs of models for baseline tower-on and tower-off (transition) tests are shown in Figure 5 and 6. Wind azimuth definition and sign convention for normal and side force are shown in Figure 7. The relative height definition $\mathrm{h} / \mathrm{L}$ is shown in Figure 8. During tests, $\mathrm{h} / \mathrm{L}$ varied from 0 (lift-off) to 0.97 . For transition (tower-off) tests, the model was mounted on two setups, the 0 -off-set for angle of attack from 0 to 50 deg and the 45 deg off-set for 30 to $90 \mathrm{deg}$, with $20 \mathrm{deg}$ overlap. Additional details on wind tunnel tests are available in ref. 6 .

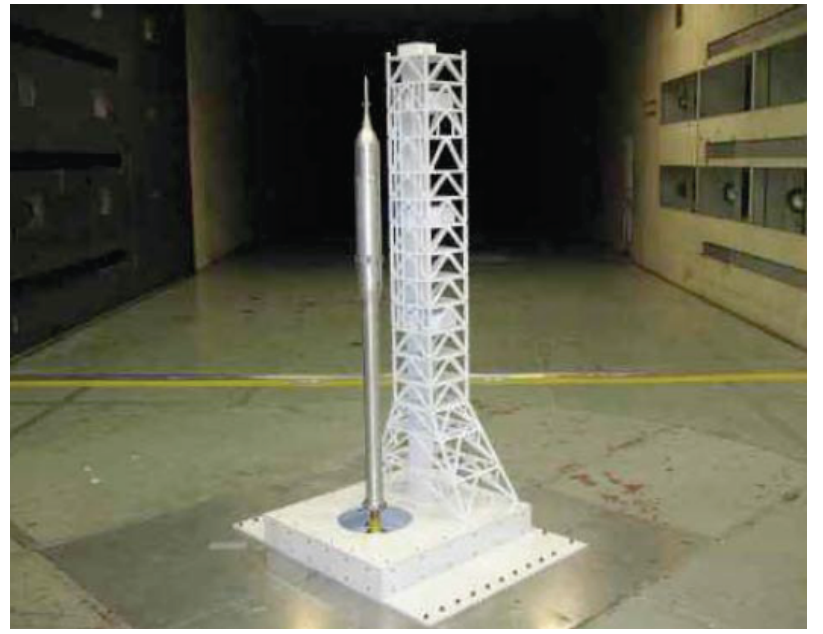

Figure 5. Test model with tower in $14 \times 22$ SWT.

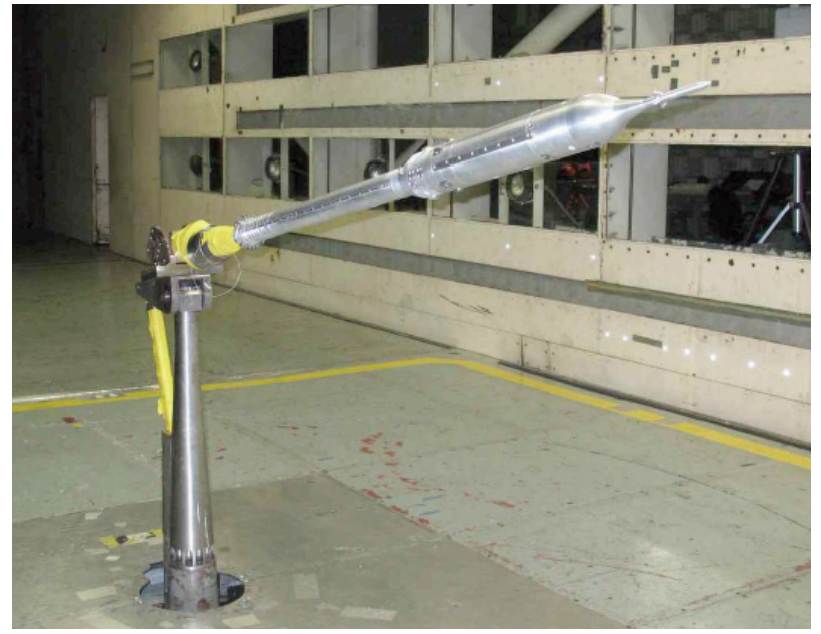

Figure 6. Model installation in 14x22 SWT for transition test.

6

American Institute of Aeronautics and Astronautics 


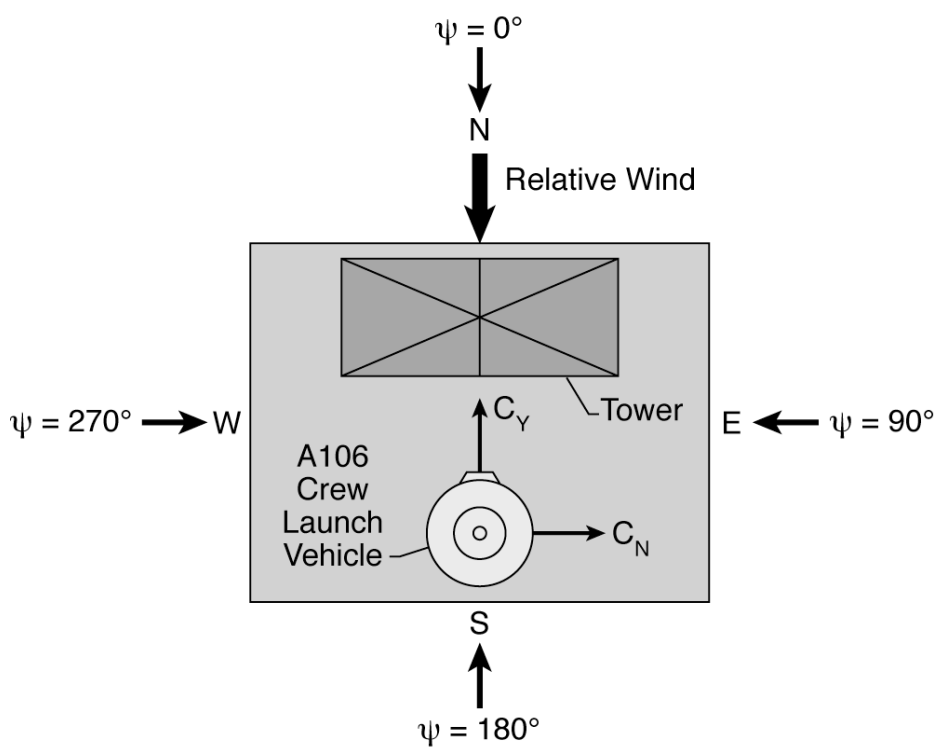

Figure 7. Wind azimuth definition.

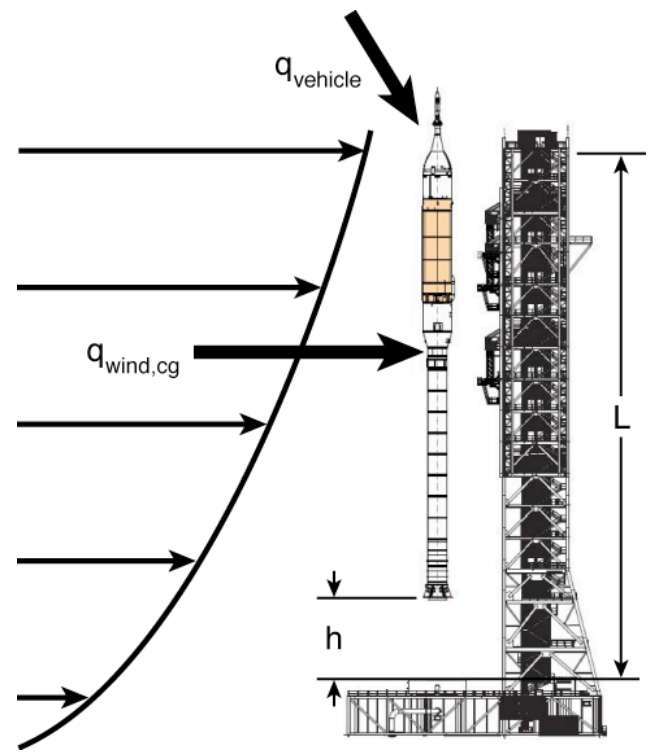

Figure 8: Definition of relative height with respect to tower.

\section{B. Ascent Force and Moment Tests}

The 6 degree-of-freedom (DOF) ascent force and moment database was developed using the wind-tunnel test data on 1\% A106 scaled model. The wind-tunnel tests were conducted at Boeing Polysonic Wind Tunnel (PSWT) from Mach 0.5 to 1.6 and at Langley Unitary Plan Wind Tunnel (UPWT) from Mach 1.6 to 4.5. The wind tunnel Reynolds numbers (based on RSRMV diameter) in PSWT and UPWT ranged from $4 \times 10^{5}$ to $10 \times 10^{6}$. The RSRMV plume effects and roll control system (RoCS) jet effects were not simulated in these wind tests.

The PSWT and UPWT tests were conducted on various $1 \%$ scale models of the A106 configuration designated $\mathrm{C}_{1}$ to $\mathrm{C}_{7}$. The $\mathrm{C}_{1}$ model was the $1 \%$ scale model of the A106 configuration including LAS nozzles and all protuberances with a height of 0.1 inches or more on the full-scale vehicle and with $10 \mathrm{BDMs}$ located at an aft location on the aft-skirt. This configuration is referred to as March 2009 OML. Protuberances that were less than 0.1 inches in height on the full-scale vehicle were not included because such small protuberances would likely be submerged in the vehicle boundary layer and have a negligible impact on the forces and moments. The $\mathrm{C}_{4}$ was a clean, $1 \%$ scale, axially symmetric model (no protuberances and no LAS nozzles). The $\mathrm{C}_{7}$ configuration was the same as $\mathrm{C}_{1}$ except the 10 BDMs moved to forward location on the aftskirt as shown in Figure 9. Test data on other models were not used in database development.

No test data were available for Mach 6.0. In view of this and lack of a better alternative, the wind tunnel derived database at Mach 4.5 was applied to Mach 6.0 .

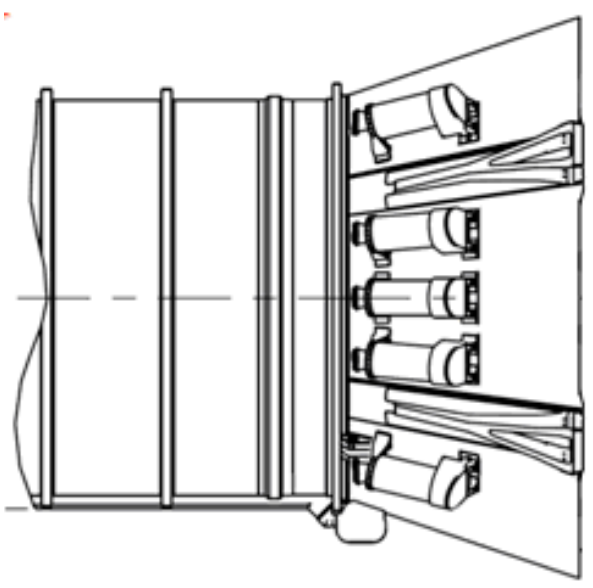

(a) A106: BDM-Fwd (A106 OML).

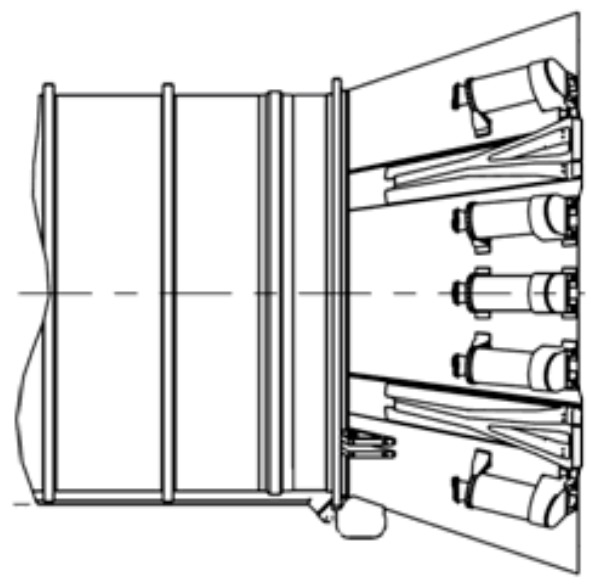

(b) A106: BDM-Aft (Mach 20, 2009 OML).

Figure 9. A106 aft geometry with BDMs located in the forward and aft positions. 


\section{CFD Solutions}

The CFD solutions were used for developing increments for, (i) Reynolds differences between wind tunnel and flight, (ii) roll control system (RoCs) aerodynamic jet interactions (JI). Figure 10 illustrates the Reynolds number differences between flight (TR5) trajectory and available wind tunnel test facilities across the first stage ascent Mach range. For PSWT and UPWT facilities, the difference is the greatest at transonic Mach numbers and decreases as Mach number approaches 6.0. The Reynolds numbers in National Transonic Facility (NTF) are one order of magnitude closer to flight Reynolds numbers but NTF testing was beyond the scope of this activity.

No adjustment to the liftoff/transition database was made for differences in Reynolds number because the uniform grit applied to the model was expected to simulate full-scale flow condition.

Most of the CFD solutions

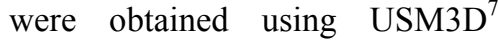
code. However, several solutions were obtained using OVERFLOW. ${ }^{8}$ For calculating Reynolds number increments, pairs of CFD solutions were obtained for wind tunnel Reynolds numbers and flight Reynolds numbers for the TR6 reference trajectory. Similarly, pairs of CFD solutions (RoCS on and off) at flight Reynolds numbers (TR6) were used for estimating aerodynamic JI incremental coefficients. Conducting power-on RoCS JI wind tunnel tests was outside the scope of this activity.

\section{Aerodynamic Analysis and Database Development}

In this section, the basic approach and methodology used for lift-off/transition, ascent and RoCS

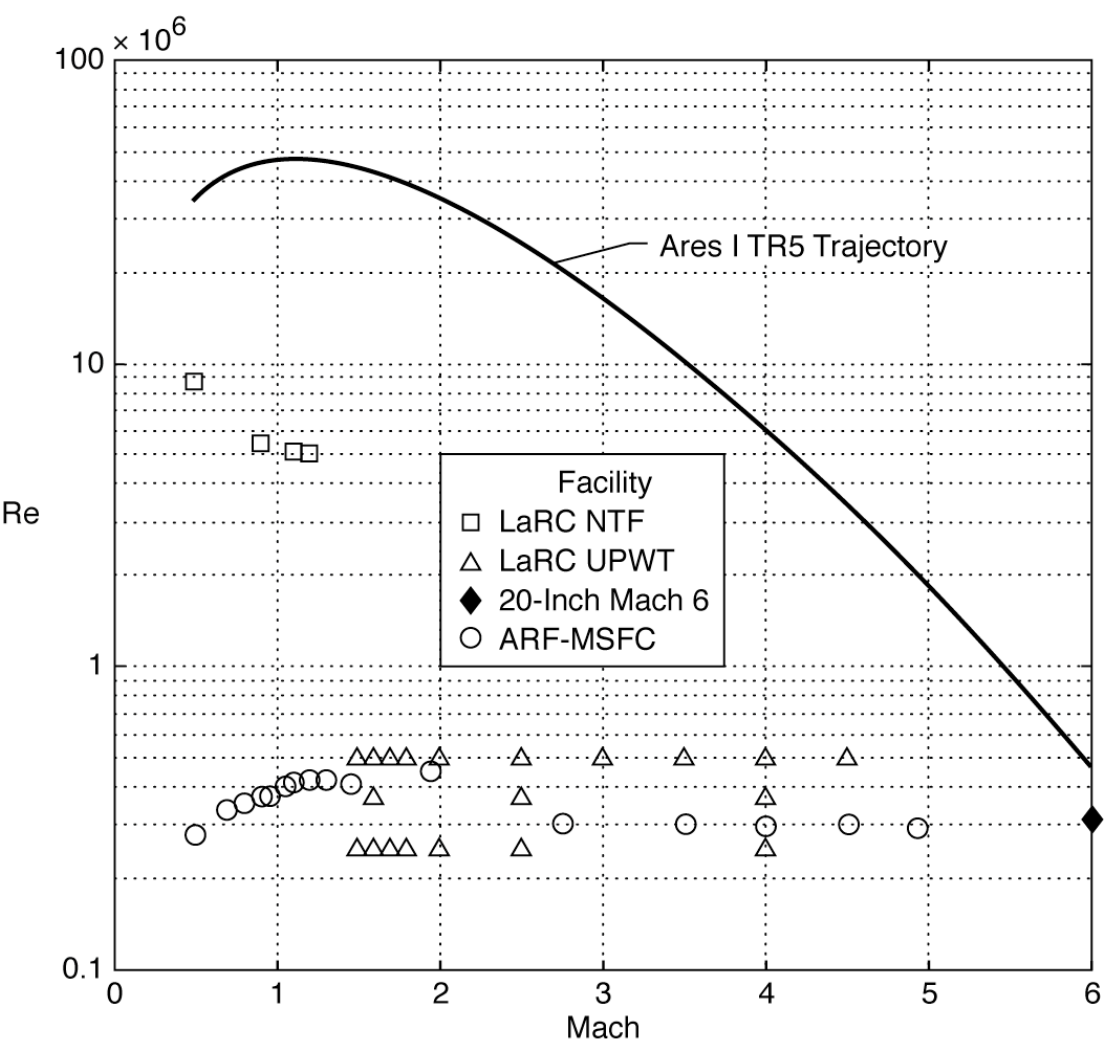

Figure 10. Comparison of Reynolds number variation with Mach for test facilities and Ares I flight trajectory. aerodynamic jet interaction databases are discussed. The details about processing wind tunnel test data and CFD solutions and generating the databases are not discussed here but are available in the Ares I aerodynamic data book. ${ }^{5}$

\section{A. Lift-Off/Transition Database}

The mathematical model for the lift-off database was developed as follows:

$$
\begin{gathered}
\mathrm{F}_{\mathrm{i}}=\mathrm{C}_{\mathrm{Fi}, \mathrm{TR}}\left(\alpha_{\mathrm{T}}, \phi\right) \mathrm{q}_{\mathrm{v}} \mathrm{S}_{\text {ref }}+\Delta \mathrm{C}_{\mathrm{Fi}, \text { tower-on }}(\mathrm{h} / \mathrm{L}, \psi) \mathrm{q}_{\text {wind }} \mathrm{S}_{\text {ref }} \\
\mathrm{M}_{\mathrm{i}}=\mathrm{C}_{\mathrm{Ti}, \mathrm{TR}}\left(\alpha_{\mathrm{T}}, \phi\right) \mathrm{q}_{\mathrm{v}} \mathrm{S}_{\text {ref }} \mathrm{d}_{\text {ref }}+\Delta \mathrm{C}_{\mathrm{Ti} \text {,tower-on }}(\mathrm{x} / \mathrm{L}, \psi) \mathrm{q}_{\text {wind }} \mathrm{S}_{\text {ref }} \mathrm{d}_{\text {ref }}
\end{gathered}
$$

Here, $\mathrm{C}_{\mathrm{F}, \mathrm{i}}$, where $\mathrm{i}=1-3$, is any one of the three aerodynamic force coefficients $\mathrm{C}_{\mathrm{A}}, \mathrm{C}_{\mathrm{N}}$ or $\mathrm{C}_{\mathrm{Y}} ; \mathrm{C}_{\mathrm{Ti}}$ is any one of the three moment coefficients $\mathrm{C}_{\mathrm{l}}, \mathrm{C}_{\mathrm{m}}$ or $\mathrm{C}_{\mathrm{n}}$, and $\Delta \mathrm{C}_{\mathrm{Fi}}$ and $\Delta \mathrm{C}_{\mathrm{Ti}}$ are corresponding incremental coefficients. The tower-on incremental coefficients were calculated by subtracting the transition (tower-off or freestream) coefficients at $\alpha_{\mathrm{T}}=90 \mathrm{deg}$ and corresponding $\phi$ from the tower-on coefficients. For this test set up, $\phi=\psi-270$. Also, $\mathrm{q}_{\mathrm{v}}$ is the net or total vehicle dynamic pressure and $\mathrm{q}_{\text {wind }}$ is the dynamic pressure due to crosswind. The terms on the left hand side $F_{i}$ and $\mathrm{M}_{\mathrm{i}}$ are the corresponding total force or moment in engineering units (lb or $\mathrm{lb}-\mathrm{ft}$ ).

8

American Institute of Aeronautics and Astronautics 
The first term on the right hand side is the transition (freestream or tower-off) force or moment component and the second term is the tower-on incremental force or moment. Here it is assumed that the tower interference effect depends only on the crosswind (transverse component of the velocity) and not on its axial component. This assumption is a consequence of facility limitations, because the entire assembly could not be positioned in $14 \times 22$ SWT at any angle of attack other than 90 deg.

The tower increment depends on wind azimuth angle $\psi$ (Figure 7) and vehicle height $(\mathrm{h} / \mathrm{L})$ relative to the tower (Figure 8). For the wind blowing towards the tower from North, $\psi=0$. When the vehicle is stationary on the pad, $\mathrm{h} / \mathrm{L}=0$ and when aft-skirt clears the tower, $\mathrm{h} / \mathrm{L}=1$. For calculating the force/moments based on Eq. (1), the wind velocity at the vehicle center of gravity shall be used as shown in Figure 8.

The database reference parameters are: the reference area is the cross sectional area of the cylindrical portion of RSRMV and the moment reference center is located at the RSRMV gimbal point which is also the origin of the reference coordinate system (Figure 4).

The test data were acquired for $\psi=0$ to 360 deg for various values of $h / L=0$ to 0.97 . However, the towerinterference effect, though very small, were found to extend beyond $\mathrm{h} / \mathrm{L}=0.97$. In view of this, based on engineering judgment, the lift-off database was extended to $h / L=1.3$ where the tower increments were set to zero.

Due to facility limitations, the data could not be acquired for azimuth angles between 70-110 deg. The missing data points were generated assuming that the flow pattern is symmetric about $\psi=180 \mathrm{deg}$. As said earlier, the test data for $\mathrm{q}=40 \mathrm{psf}$ and $80 \mathrm{psf}$ were combined assuming that they are repeat runs. Data from multiple runs were averaged to produce a single set of runs for a given combination of height and azimuth angles. The transition test data was acquired in pitch and roll fashion. That is, the test model was pitched to a desired angle and then rolled from 0 to $360 \mathrm{deg}$. In view of this, it was convenient to generate the transition database first in missile axis format $\left(\alpha_{\mathrm{T}}, \phi\right)$ as in Eq.(1) and then convert to the body axis format $(\alpha, \beta)$ format. The procedure used for these conversions is discussed in the A106 aerodynamic data book ${ }^{5}$.

\section{B. Ascent Database}

This database covers Mach numbers ranging from 0.5 to 6.0, angle of attack $(\alpha)$ and sideslip angle ( $\beta$ ) each from $-7 \mathrm{deg}$ to $+7 \mathrm{deg}\left(\alpha_{\mathrm{T}}=10 \mathrm{deg}\right)$ and does not include any power-on effects due to RoCS jets or RSRMV plume. The aerodynamic jet interaction due to RoCS is discussed in the next section. The base force correction due to RSRMV plume effects are estimated separately as discussed in the A106 aerodynamic data book ${ }^{5}$.

For Mach 0.5 to 1.6, the PSWT data from Test 873 on a 1\% scale model of the A106 were used. For Mach 1.6 to 4.5, the data from UPWT tests 1843 and 1992 also on a 1\% scale model of A106 were used.

As said earlier, the test data on $\mathrm{C}_{1}, \mathrm{C}_{4}$ and $\mathrm{C}_{7}$ models were used in the development of the first-stage ascent database. The test data on the axially symmetric $\mathrm{C}_{4}$ configuration were used to adjust the $\mathrm{C}_{1}$ test data for tunnel flow angularities, model and balance asymmetries as explained later.

The wind-tunnel test data were obtained in two steps: i) pitch polars ( $\alpha_{\mathrm{T}}$ variation) at a zero roll, ii) roll sweeps with $\phi$ varying from 0 to $360 \mathrm{deg}$ for fixed $\alpha_{\mathrm{T}}$. The PSWT test data were obtained continuously as the model was rolled, but the UPWT data were obtained in 15 deg increments.

The force and moment database was developed first in the missile axes system $\left(\alpha_{\mathrm{T}}, \phi\right)$ in two steps: i) pitch sweep aerodynamic coefficients at zero roll angle, ii) incremental coefficients to account for roll angle effects. The total coefficients were obtained by adding these two components.

The reference parameters for this database are same as those for lift-off/transition database.

1. Aerodynamic Model

The missile axis aerodynamic model was developed as:

$$
\mathrm{C}_{\mathrm{i}}\left(\mathrm{M}, \alpha_{\mathrm{T}}, \phi\right)=\mathrm{C}_{\mathrm{b}, \mathrm{i}}\left(\mathrm{M}, \alpha_{\mathrm{T}}, \phi=0\right)+\Delta \mathrm{C}_{\mathrm{i}}\left(\mathrm{M}, \alpha_{\mathrm{T}}, \phi\right)
$$

Here, $C_{i}$, where $i=1-6$, is any one of the six aerodynamic coefficients $C_{A F}, C_{N}, C_{Y}, C_{1}, C_{m}, C_{n}$. The first term on the right-hand side gives the value of $\mathrm{C}_{\mathrm{i}}$ at $\phi=0$, called the baseline coefficient estimated using the pitch sweep data. The second term gives the incremental coefficients due to the roll angle estimated using roll sweep data. The procedure to estimate these two terms is as follows:

2. Baseline Coefficient

The baseline coefficients were evaluated as

$$
\mathrm{C}_{\mathrm{b}, \mathrm{i}}\left(\mathrm{M}, \alpha_{\mathrm{T}}, \phi=0\right)=\mathrm{C}_{4, \mathrm{i}}\left(\mathrm{M}, \alpha_{\mathrm{T}}, \phi=0\right)+\left(\mathrm{C}_{1, \mathrm{i}}\left(\mathrm{M}, \alpha_{\mathrm{T}}, \phi=0\right)-\mathrm{C}_{4, \mathrm{i}}\left(\mathrm{M}, \alpha_{\mathrm{T}}, \phi=0\right)\right)
$$

9

American Institute of Aeronautics and Astronautics 
The first term on the right-hand side of eq. (4) is the aerodynamic coefficient of the axially symmetric $\mathrm{C}_{4}$ configuration, and the second term gives the increment due to protuberances. For $\mathrm{C}_{4}$ configuration, the normal force and pitching moment coefficients were adjusted so that they are equal to zero at $\alpha_{\mathrm{T}}=0$ and have anti-symmetric variation with $\alpha_{\mathrm{T}}$. The $\mathrm{C}_{4}$ axial force coefficient was adjusted to have symmetric variation with $\alpha_{\mathrm{T}}$. This adjustment is an approximation to compensate for the tunnel flow angularities and balance asymmetries that would be present if the $\mathrm{C}_{1}$ test data were used directly. Also, taking increments between the $\mathrm{C}_{1}$ and $\mathrm{C}_{4}$ test data tends to cancel out such errors in the average sense. Then, these increments were added to the adjusted $\mathrm{C} 4$ coefficients to obtain the total baseline coefficients for the $\mathrm{C}_{1}$ configuration.

The side force, rolling, and yawing moment coefficients are zero for $\mathrm{C}_{4}$ but not for $\mathrm{C}_{1}$ due to the effect of protuberances.

3. Incremental Coefficients due to Roll Angle: These incremental coefficients were estimated as

$$
\Delta \mathrm{C}_{\mathrm{i}}\left(\mathrm{M}, \alpha_{\mathrm{T}}, \phi\right)=\left[\mathrm{C}_{1, \mathrm{i}}\left(\mathrm{M}, \alpha_{\mathrm{T}}, \phi\right)-\mathrm{C}_{4, \mathrm{i}}\left(\mathrm{M}, \alpha_{\mathrm{T}}, \phi\right)\right]-\left[\mathrm{C}_{1, \mathrm{i}}\left(\mathrm{M}, \alpha_{\mathrm{T}}, \phi=0\right)-\mathrm{C}_{4, \mathrm{i}}\left(\mathrm{M}, \alpha_{\mathrm{T}}, \phi=0\right)\right]
$$

Here, the first two terms on the right-hand side gives the incremental coefficient due to roll angle for the $\mathrm{C}_{1}$ configuration with respect to the $\mathrm{C}_{4}$ configuration. The next two terms give the value of that incremental coefficient at zero roll angle, which is subtracted out to avoid double bookkeeping because this term is already included in the baseline coefficient in Eq. (4).

Roll sweep increments at $\alpha_{\mathrm{T}}=0$ deg need special attention because the converted body axis aerodynamic coefficients must be invariant with $\phi$ because the body axis system rolls with body while missile axis system remains fixed at zero roll orientation. To ensure this, the calculated missile axis roll sweep increments for all roll angles were converted to the body axis. Ideally, they should all be identical but they were not. Therefore, these values were averaged to obtain a single value for each of the six coefficient. Then, these body axis averaged coefficients were converted back to the missile axis coefficients. As a result, these adjusted coefficients for the $\mathrm{C}_{1}$ configuration are constant in the body axis system but show sinusoid variation with $\phi$ in the missile axis system except for axial force and rolling moment coefficients.

4. Total Coefficients for $C_{l}$

These are obtained by adding the baseline coefficients and the roll sweep increments.

$$
\mathrm{C}_{1, \mathrm{i}}\left(\mathrm{M}, \alpha_{\mathrm{T}}, \phi\right)=\mathrm{C}_{1, \mathrm{i}}\left(\mathrm{M}, \alpha_{\mathrm{T}}, \phi=0\right)+\Delta \mathrm{C}_{1, \mathrm{i}}\left(\mathrm{M}, \alpha_{\mathrm{T}}, \phi\right)
$$

\section{BDM Increments}

The $\mathrm{C}_{7}$ configuration has the $10 \mathrm{BDMs}$ at the forward location on the aft skirt as in A106 configuration. However, when PSWT and UPWT wind tunnel test campaign was conducted during July-September 2009, then official A106 configuration featured 10 BDMs at aft location on the aft-skirt (Figure 9). The OML change was anticipated but did not become official until October 2009. However, in anticipation of this change, some limited test data were acquired for $\mathrm{C}_{7}$ configuration. These test data are used to estimate the $\mathrm{C}_{7}$ to $\mathrm{C}_{1}$ increments as follows:

$$
\Delta \mathrm{C}_{\mathrm{bdm}, \mathrm{i}}\left(\mathrm{M}, \alpha_{\mathrm{T}}, \phi\right)=\mathrm{C}_{7, \mathrm{i}}\left(\mathrm{M}, \alpha_{\mathrm{T}}, \phi\right)-\mathrm{C}_{1, \mathrm{i}}\left(\mathrm{M}, \alpha_{\mathrm{T}}, \phi\right)
$$

\section{Total Coefficients for A106 Configuration}

The total coefficients in missile axis system were obtained by combining the $\mathrm{C}_{1}$ coefficients with the BDM increments as follows:

$$
\mathrm{C}_{\mathrm{i}}\left(\mathrm{M}, \alpha_{\mathrm{T}}, \phi\right)=\mathrm{C}_{1, \mathrm{i}}\left(\mathrm{M}, \alpha_{\mathrm{T}}, \phi\right)+\Delta \mathrm{C}_{\mathrm{bdm}, \mathrm{i}}\left(\mathrm{M}, \alpha_{\mathrm{T}}, \phi\right)
$$

These coefficients were then converted to body axis $(\alpha, \beta)$ format. The procedure used for these conversions is discussed in the A106 aerodynamic data book ${ }^{5}$.

\section{Reynolds Number Increments}

The increments for all six aerodynamic coefficients were calculated by taking the differences between the pairs of CFD solutions for identical Mach, $\alpha_{\mathrm{T}}$, and $\phi$ conditions, one at wind tunnel test Reynolds number and the other at full scale flight Reynolds number. These increments were added to the total coefficients in Eq. (8) to obtain the mis- 
sile axis aerodynamic coefficients at flight Reynolds numbers that were converted to body axis $(\alpha, \beta)$ format. Additional details of are available in A106 aerodynamic data book. ${ }^{5}$

\section{RoCS JI Incremental Database}

This database provides the incremental aerodynamic JI coefficients due to RoCS and does not include the primary rolling moment due to RoCS thrusters. The incremental coefficients were calculated using the pairs of CFD solutions for power-on (thrusters firing) and power-off (no firing) and these incremental coefficients are based on the total RoCS thrust. These incremental coefficients are provided in body axis system but as function of missile axis variables $\alpha_{\mathrm{T}}$ and $\phi$.

The RoCS thruster locations are shown in Figure 11 and the sign convention used for the induced aerodynamic rolling moment are shown in Figure 12. The positive firing jets produce positive rolling moment and vice versa for negative firing jets. The RoCS housing contains three thrusters on the top and three on the bottom. Nominally, only two thrusters on the top and bottom are used, the third (redundant) thruster used only when the roll error or roll rate exceeds certain specified values. Most of the CFD solutions were obtained for two thrusters firing and only a few solutions were obtained for three thrusters firing, but not enough to develop a database. However, these CFD solutions indicated that the third thruster influence on induced aerodynamic coefficients was small. In view of this, the database was developed using the CFD solutions for two thrusters firing and the effect of the third thruster was accounted by specifying higher dispersion bounds when it was used.

The altitude, Mach and freestream conditions for input to CFD solutions were taken from the reference trajectory TR6. However, the database is supposed to be used for dispersed conditions. In view of this, some CFD solutions were obtained for various combinations of Mach, altitude, and freestream static pressures corresponding to TD6 (dispersed trajectory) envelopes. These solutions indicated that the calculated RoCS JI increments were not very sensitive to changes in dispersed freestream conditions but the corresponding forces/moments if based on freestream dynamic pressure would be unusually sensitive to dispersed dynamic pressure that varies by more than a factor of 2 in relation to the nominal dynamic pressure. Since the primary source of RoCS JI incremental coefficients is the thrust, it was decided to estimate RoCS JI incremental coefficients based on thrust. With a thrust-based model, the RoCS JI incremental forces/moments are

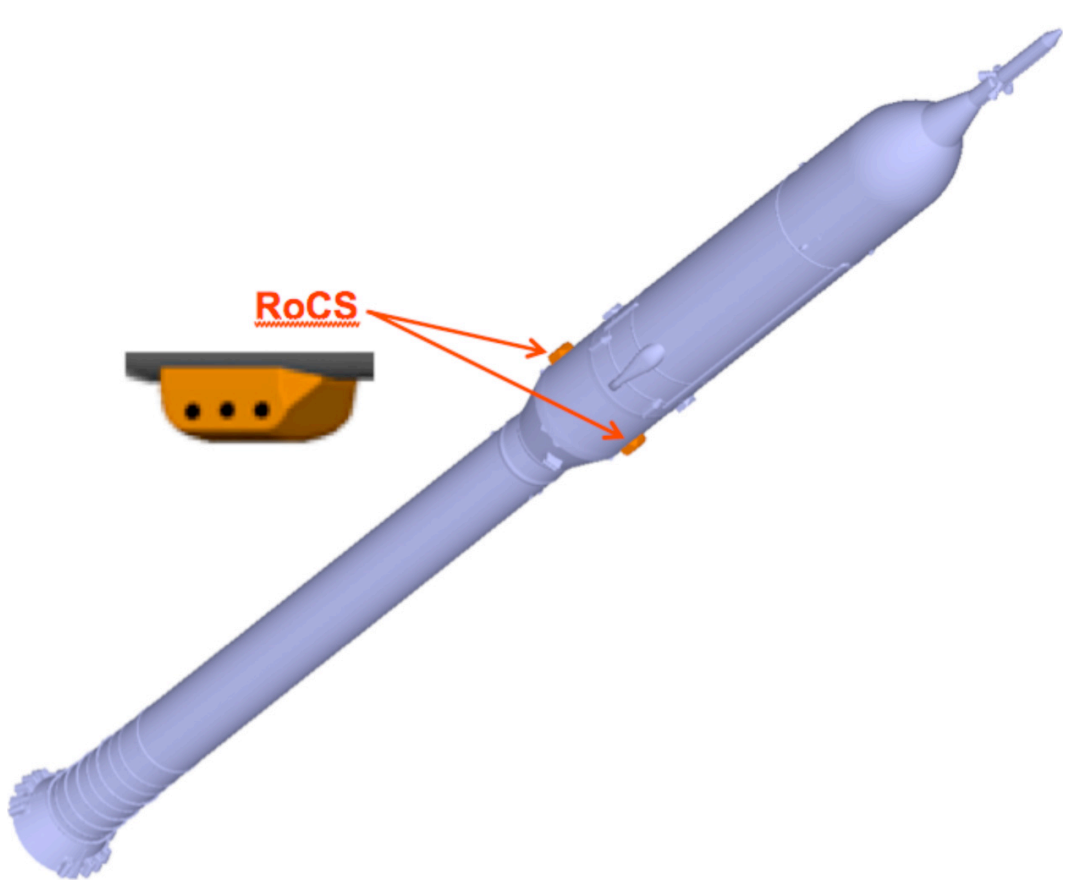

Figure 11. Schematic illustration of RoCS housing on A106 vehicle.

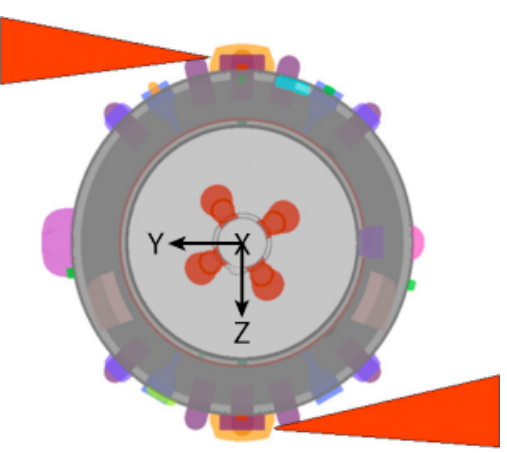

(a) Negative Firing.

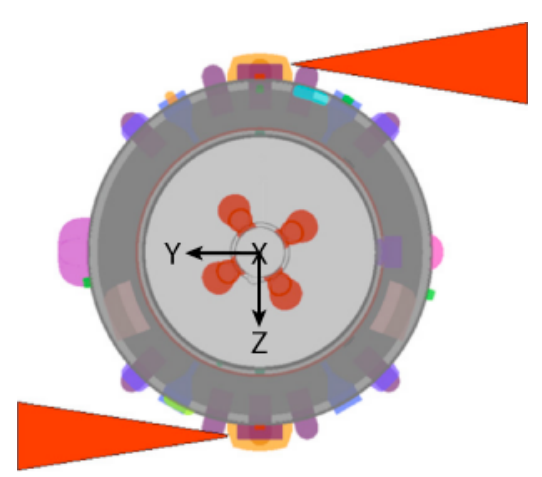

(b) Positive Firing.
Figure 12. Sign convention for RoCS firing.

11

American Institute of Aeronautics and Astronautics 
relatively less sensitive to changes in freestream conditions, particularly the dynamic pressure. The influence of freestream condition was accounted by adjusting RoCS thrust for variations in Mach, altitude and freestream static pressure. Additional details are available in A106 aerodynamic data book ${ }^{5}$.

The net thrust produced by the RoCS thruster was estimated as follows:

$$
\mathrm{T}_{\mathrm{adj}}=\mathrm{T}_{\mathrm{vac}}-\mathrm{P}_{\mathrm{atm}} * \mathrm{~A}_{\mathrm{e}}
$$

where $T_{\text {vac }}$ is the vacuum thrust, $A_{e}$ is the exit area of the thruster, and $\mathrm{P}_{\mathrm{atm}}$ is the freestream static atmospheric pressure. Figure 13 shows the adjusted thrust variation with Mach along the nominal ascent trajectory (TR7).

The main induced aerodynamic jet interaction effect is on rolling moment accompanied by a small change in axial force. Other incremental coefficients were very small and set to zero in the RoCS JI database but included in uncertainty ${ }^{5}$.

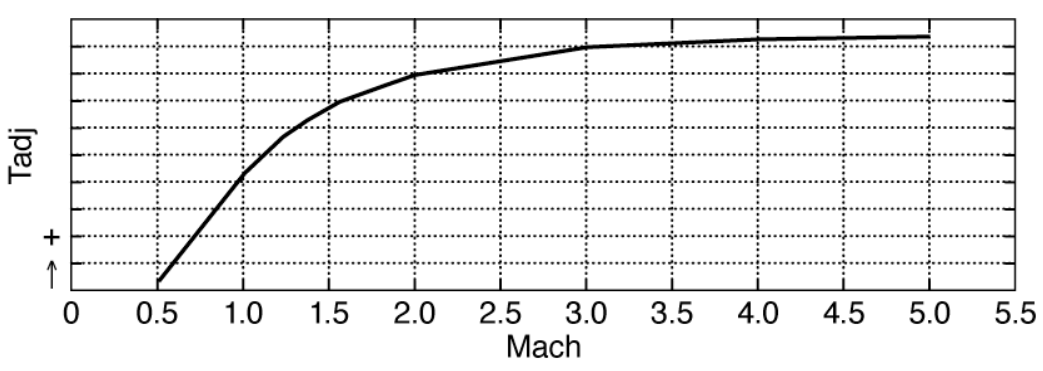

Figure 13. Adjusted thrust with altitude and dynamic pressure.

The thrust based RoCS JI incremental axial force and rolling moment coefficients were estimated as follows:

$$
\begin{gathered}
\Delta \mathrm{C}_{\mathrm{AT}, \mathrm{JI}}=\Delta \mathrm{F}_{\mathrm{A}, \mathrm{JI}} / \mathrm{T}_{\mathrm{adj}} \\
\Delta \mathrm{C}_{\mathrm{IT}, \mathrm{JI}}=\Delta \mathrm{L}_{\mathrm{JI}} /\left(\mathrm{T}_{\mathrm{adj}} * \mathrm{~d}_{\mathrm{ref}}\right)
\end{gathered}
$$

Here, $\Delta \mathrm{F}_{\mathrm{A}, \mathrm{JI}}$ and $\Delta \mathrm{L}_{\mathrm{JI}}$ are the estimated CFD aerodynamic jet interaction incremental axial force and rolling moments respectively.

1 Negative Firing Jets

For Mach 0.5 to 1.6 , a response surface in $\mathrm{M}, \alpha_{\mathrm{T}}$ and $\phi$ was constructed for the calculated CFD rolling moment increments. However, for Mach $>1.6$, the roll angle has very little effect on RoCS JI rolling moment increments. In view of this, the incremental rolling moment coefficients were roll averaged leaving only Mach and $\alpha_{\mathrm{T}}$ dependence. The incremental axial force coefficient was roll averaged at each $\alpha_{\mathrm{T}}$ for all Mach numbers.

2 Positive Firing Jets

Majority of the CFD solutions were obtained for negative thruster firing and only a few for positive firing. This approach was taken based on experience with the previous A103 configuration for which the mirroring (symmetry) concept worked well. That is, the mirrored negative firing incremental coefficients compared well with the actual increments calculated from positive firing CFD solutions. However, for A106 configuration the mirroring principle did not work as well apparently due protuberance changes. However, owing to schedule and resource limitations, it was not possible to go back and obtain the requisite number of positive firing CFD solutions. In view of this, the positive firing incremental coefficients were generated using the mirroring principle but the dispersion bounds for positive firing were set much higher to account for these discrepancies in modeling.

Additional information on RoCS JI database development is available in A106 aerodynamic data book ${ }^{5}$.

\section{Results and Discussion}

The lift-off/transition, ascent and RoCS JI databases contain a vast amount of data and it is not feasible to present detail plots in this paper. In view of this, only sample results are presented here.

The tower incremental side force and total side force coefficients are shown in Figures 14 and 15 for various relative heights $\mathrm{h} / \mathrm{L}$ from 0 to 0.97 . The magnitude of incremental side force coefficient is largest for $\mathrm{h} / \mathrm{L}=0$ (liftoff) and diminishes as $\mathrm{h} / \mathrm{L}$ increases and approaches zero for $\mathrm{h} / \mathrm{L}=0.97$, when the vehicle is just about to clear the tower. A positive side force tends to push the vehicle towards the tower and a negative side force away from the tower (Figure 7). Therefore, a positive increment in side force implies that the tower effect is adverse and a negative side force increment implies a beneficial tower effect. The side force due to North wind tends to push the vehicle away from tower. However, the corresponding tower interference is adverse so that the net side force tending to 
push the vehicle away from the tower is diminished. Similarly, a South wind tends to push the vehicle towards the tower and the beneficial tower interference effect tends to alleviate this tendency. The tower interference effect due to East or West winds is relatively small.

The normal force increments and total values are presented in Figures 16 and 17 for various values of $h / L$. The normal force increments are relatively small so that total normal force coefficient is almost the same for all values of $h / L$.

A schematic illustration of side force and normal force incremental coefficients for azimuth variation from 0 to 360 for $\mathrm{h} / \mathrm{L}=0$ is shown in Figure 18. The side force increments are slightly asymmetrical with respect to 0 or $180 \mathrm{deg}$ azimuth because of protuberance effects.

The transition aerodynamic coefficients are shown in Figures 19 to 23 for angles of attack $-90 \mathrm{deg}$ to $90 \mathrm{deg}$ for sideslip from $-90 \mathrm{deg} 90$ deg. The variation of axial force coefficient with angle of attack for various sideslip is shown in Figure 19. The normal force and pitching moment coefficients increase with angle of attack and vice versa for negative angles of attack (Figures 20 and 21). The side force and yawing moment coefficient also increase with sideslip and vice versa for negative sideslip (Figures 22 and 23).

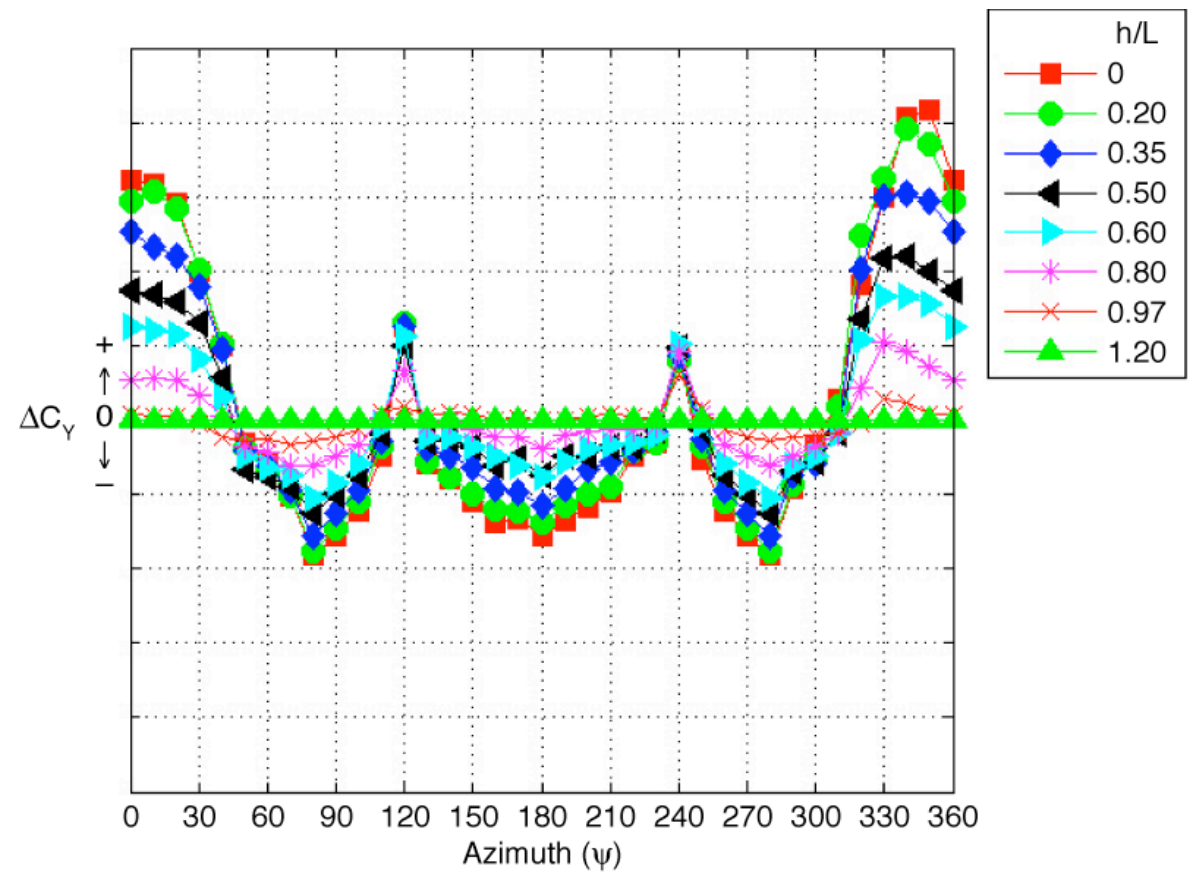

Figure 14. Side force coefficient, tower-on increments.

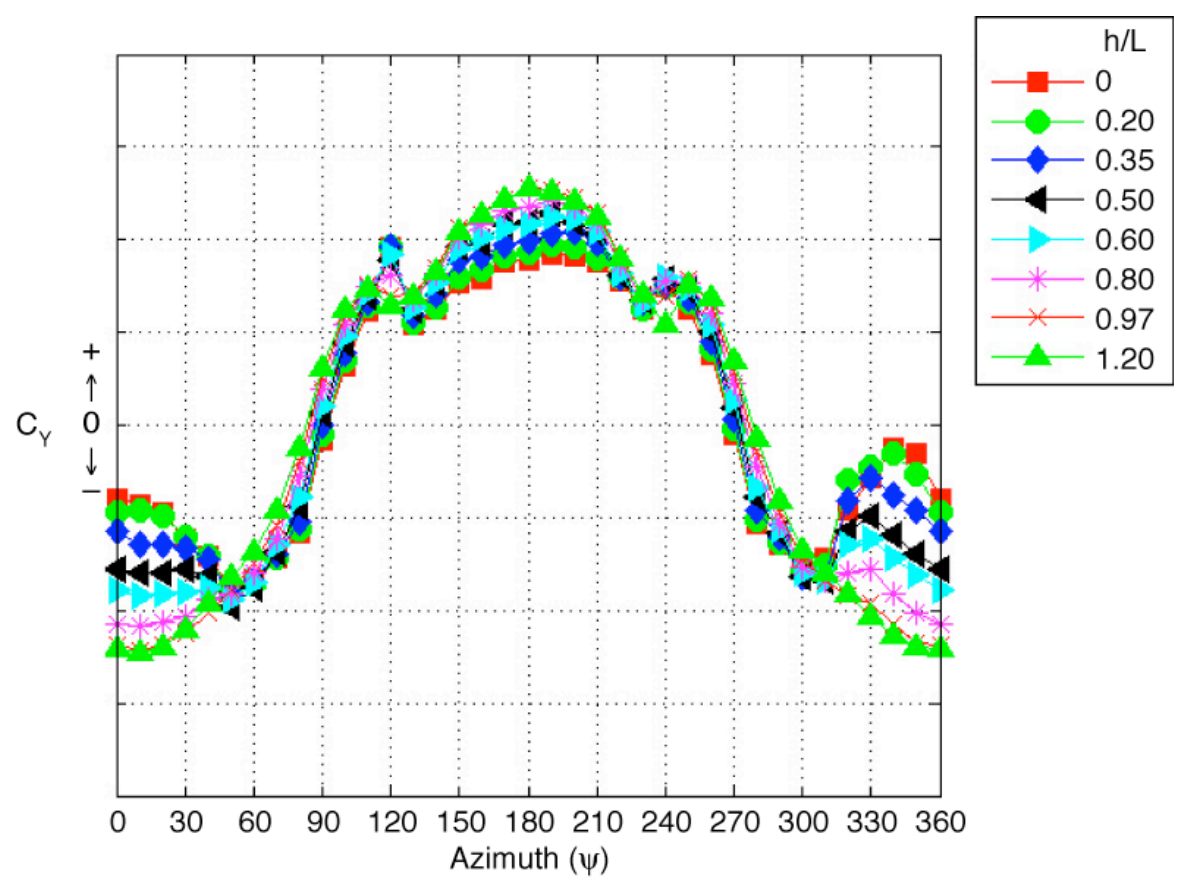

Figure 15. Tower-On total side force coefficients.

American Institute of Aeronautics and Astronautics 


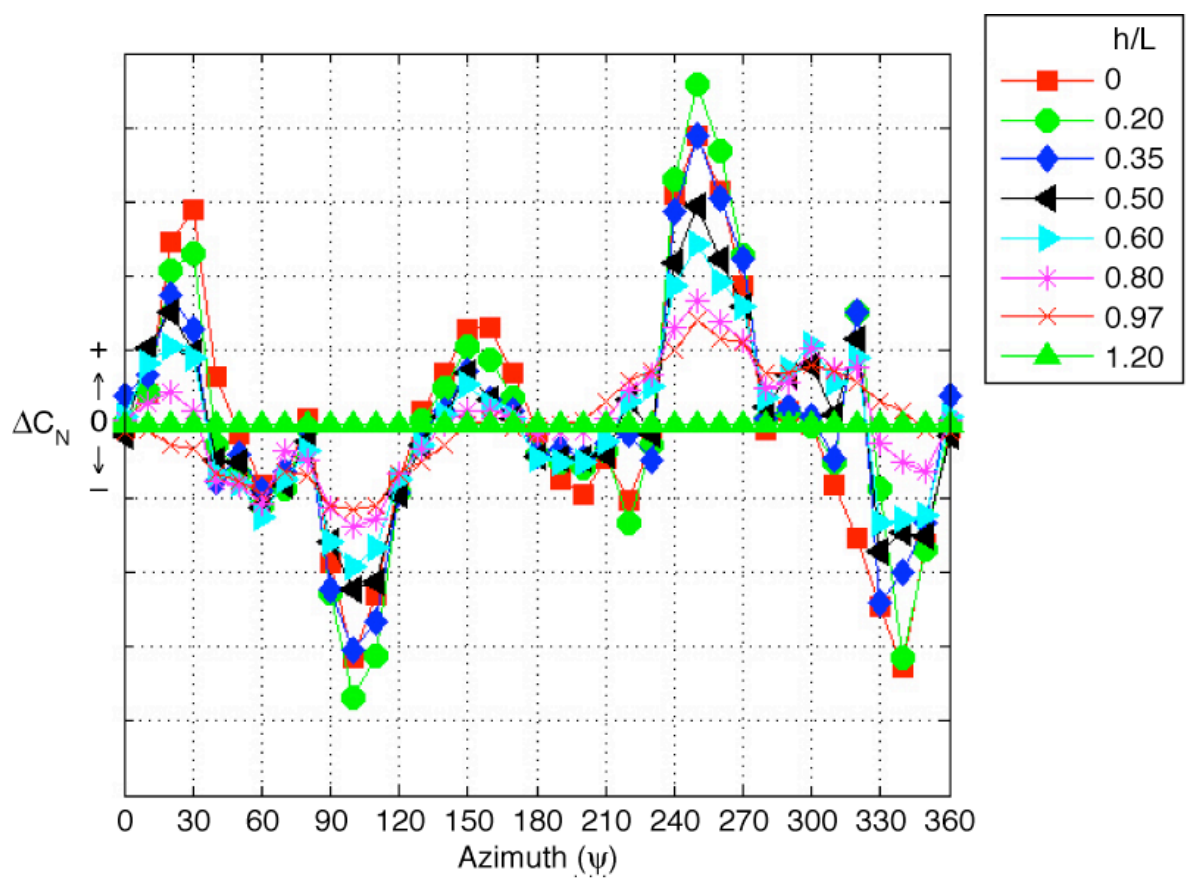

Figure 16. Tower-On normal force coefficient increments.

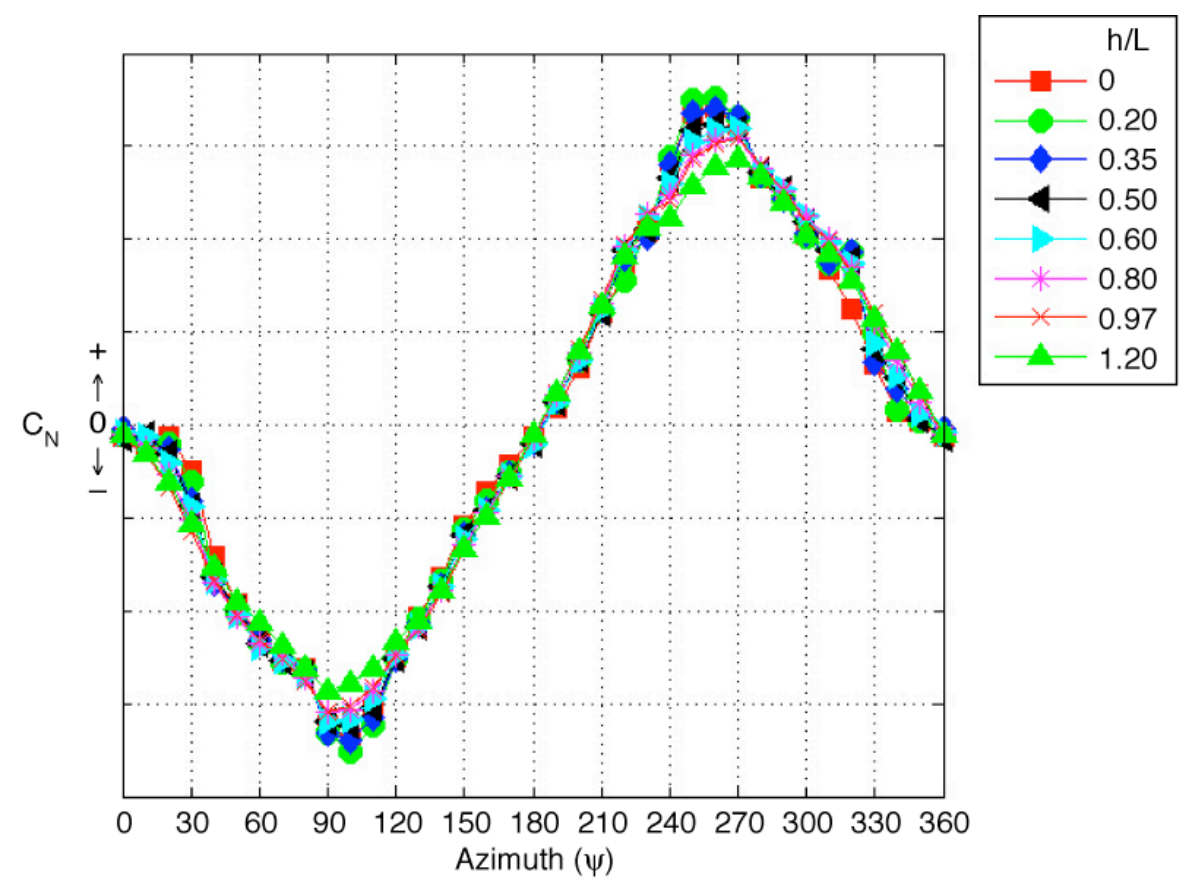

Figure 17. Tower-On total normal force coefficient.

14

American Institute of Aeronautics and Astronautics 


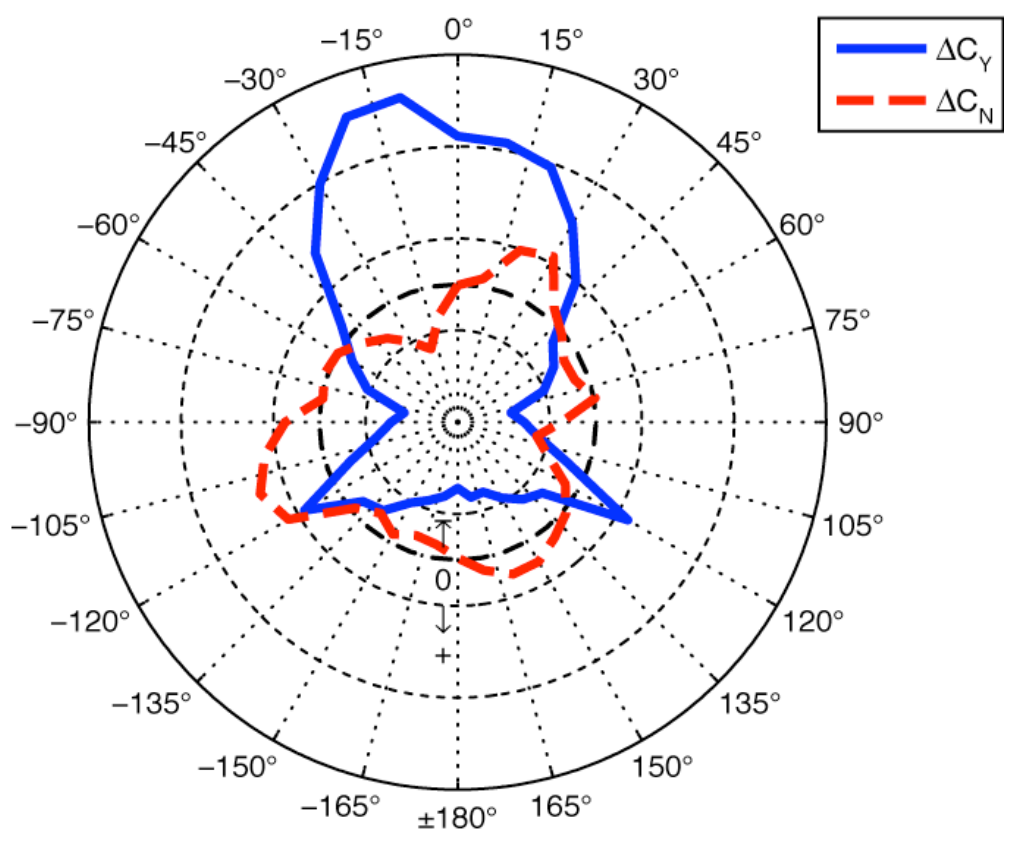

Figure 18. Schematic representation of tower effect at $h / L=0$.

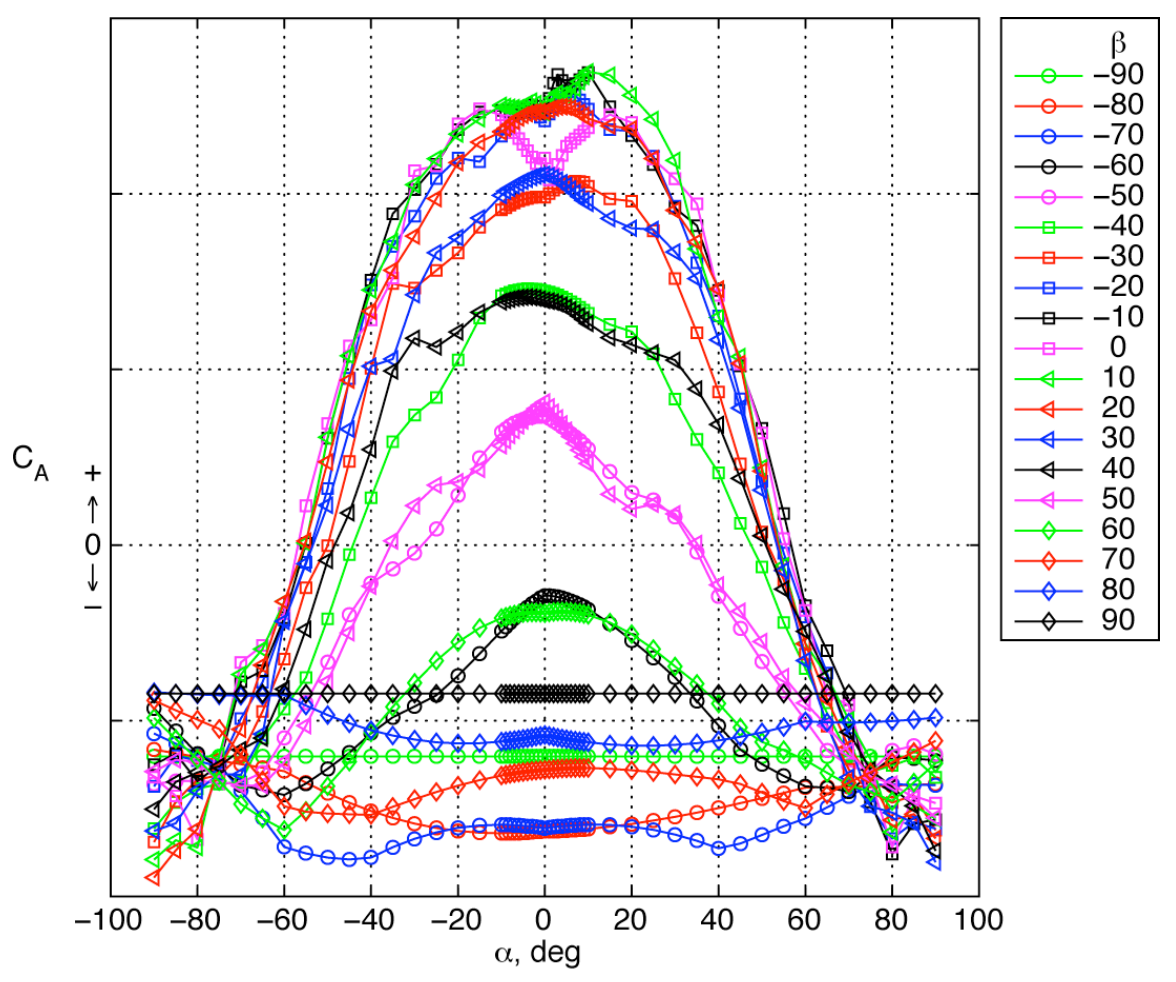

Figure 19. Axial force coefficient (transition database). 


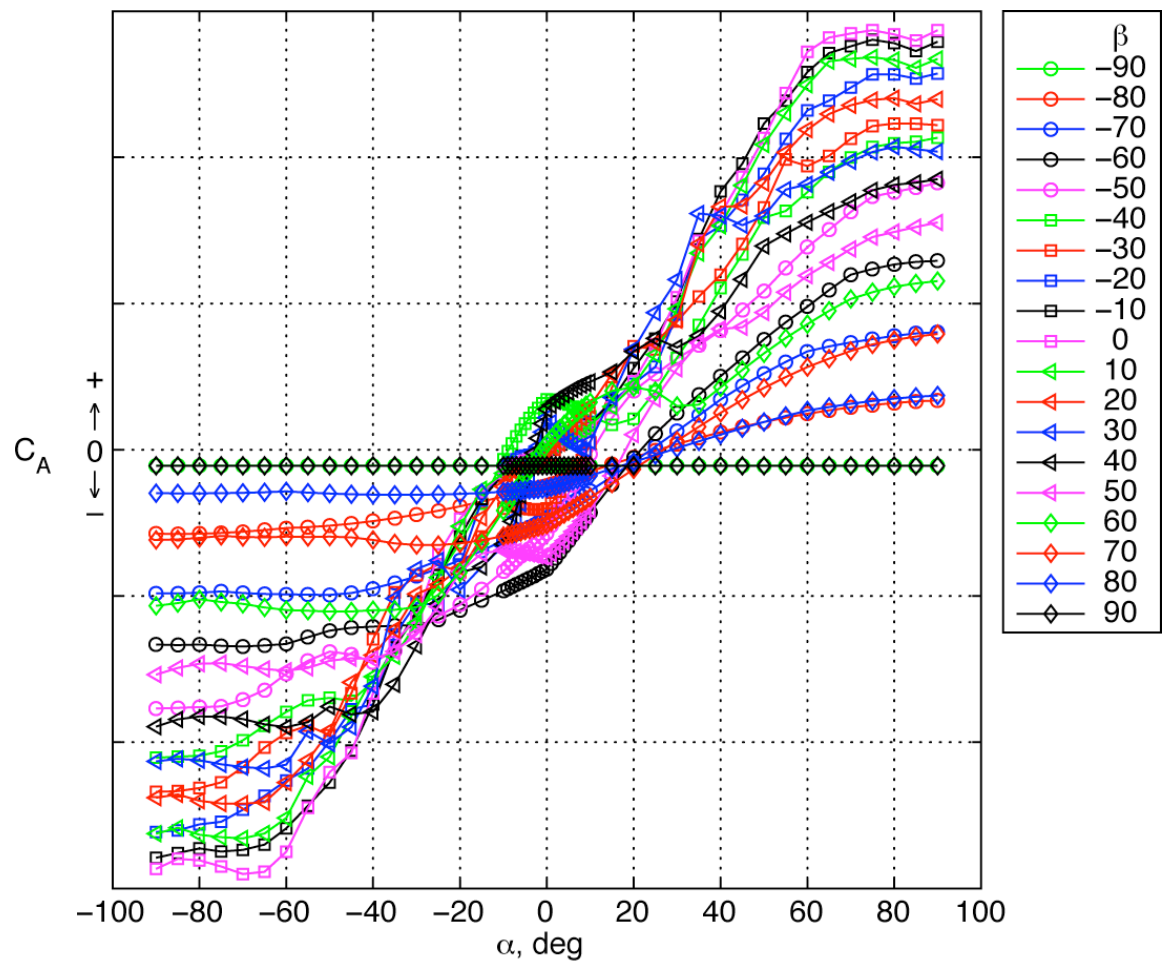

Figure 20. Normal force coefficient (transition database).

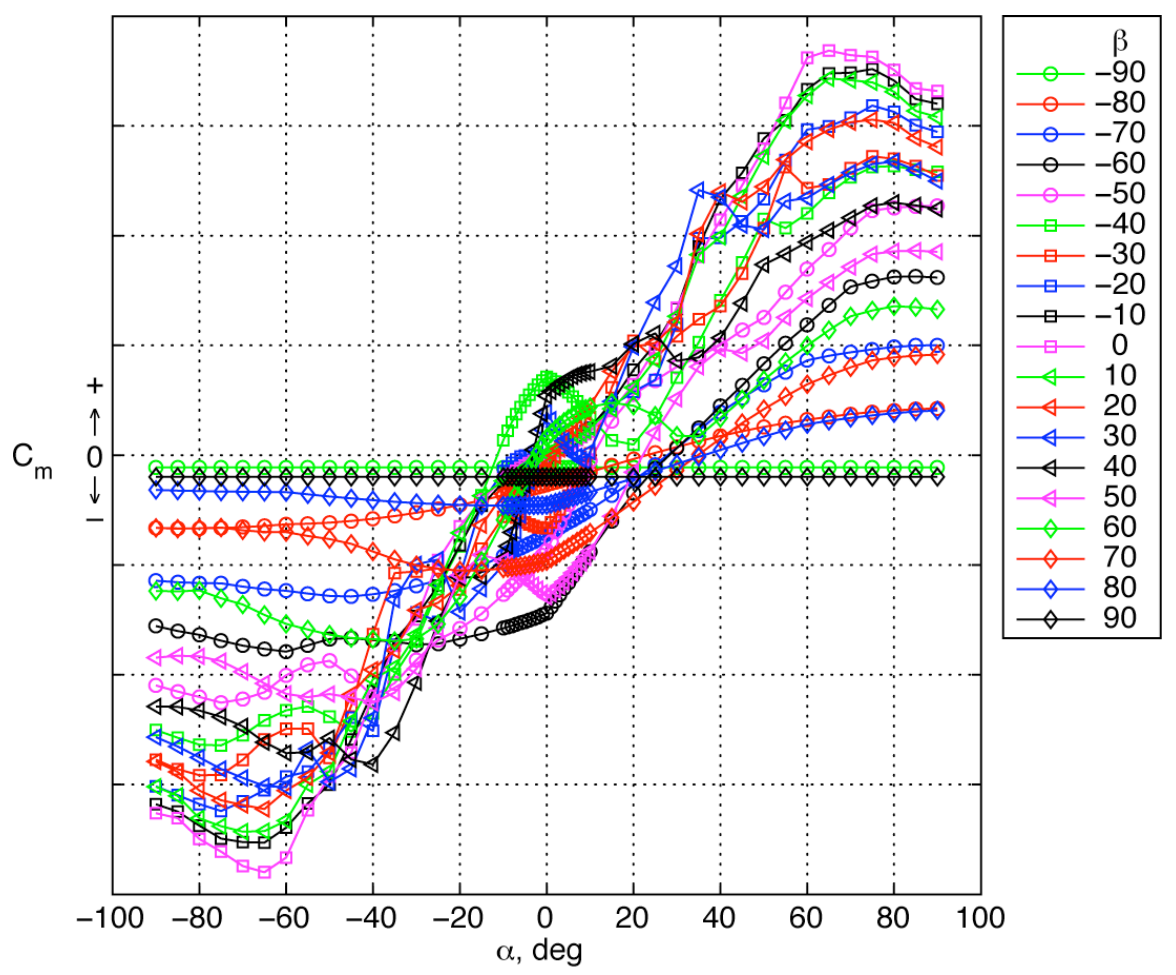

Figure 21. Pitching moment coefficient (transition database).

16

American Institute of Aeronautics and Astronautics 


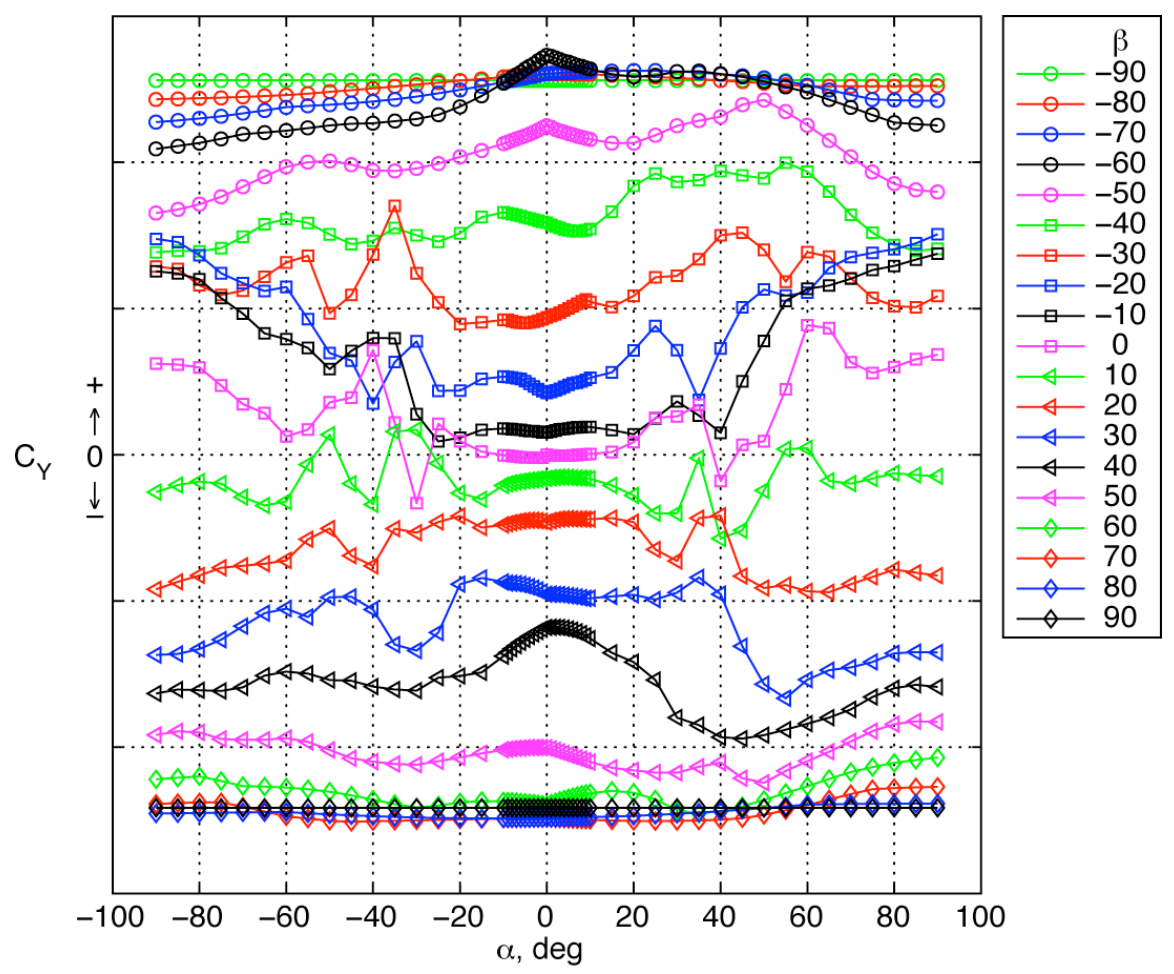

Figure 22. Side force coefficient (transition database).

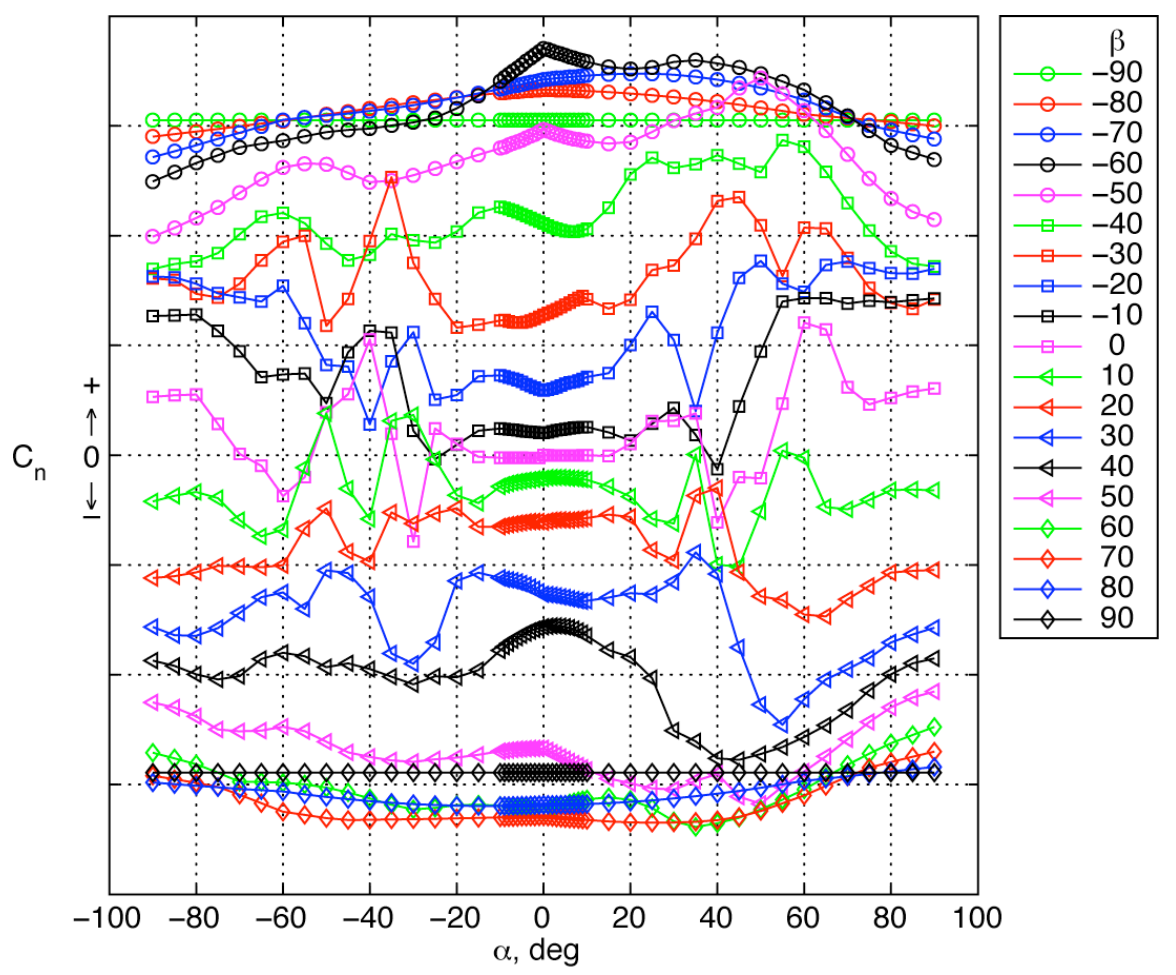

Figure 23. Yawing moment coefficient (transition database).

17

American Institute of Aeronautics and Astronautics 
Sample results of ascent database for Mach 0.5 and angle of attack/sideslip ranging from -7 to $+7 \mathrm{deg}$ are shown in Figures 24 to 29. The axial force coefficient is shown in Figure 24. The normal force and pitching moment coefficients increase with angle of attack and vice versa for negative angle of attack (Figures 25 and 26). The side force and yawing moment coefficients exhibit the same behavior with sideslip (Figures 27 and 28). The variation of rolling moment is presented in Figure 29 in missile axes system $\left(\alpha_{\mathrm{T}}, \phi\right)$ because it is physically more intuitive to view rolling moment coefficient variation in this format. It is interesting to note that the rolling moment coefficient is negative for $\phi=0$ to $180 \mathrm{deg}$, switches sign around $180 \mathrm{deg}$ and assumes positive values subsequently. Ideally, the negative and positive areas should be equal so that the net area under the rolling moment curve is zero. However, due to nonlinear interactions between protuberances the positive and negative areas are not equal in magnitude and the net area is nonzero as noticed in Figure 29.

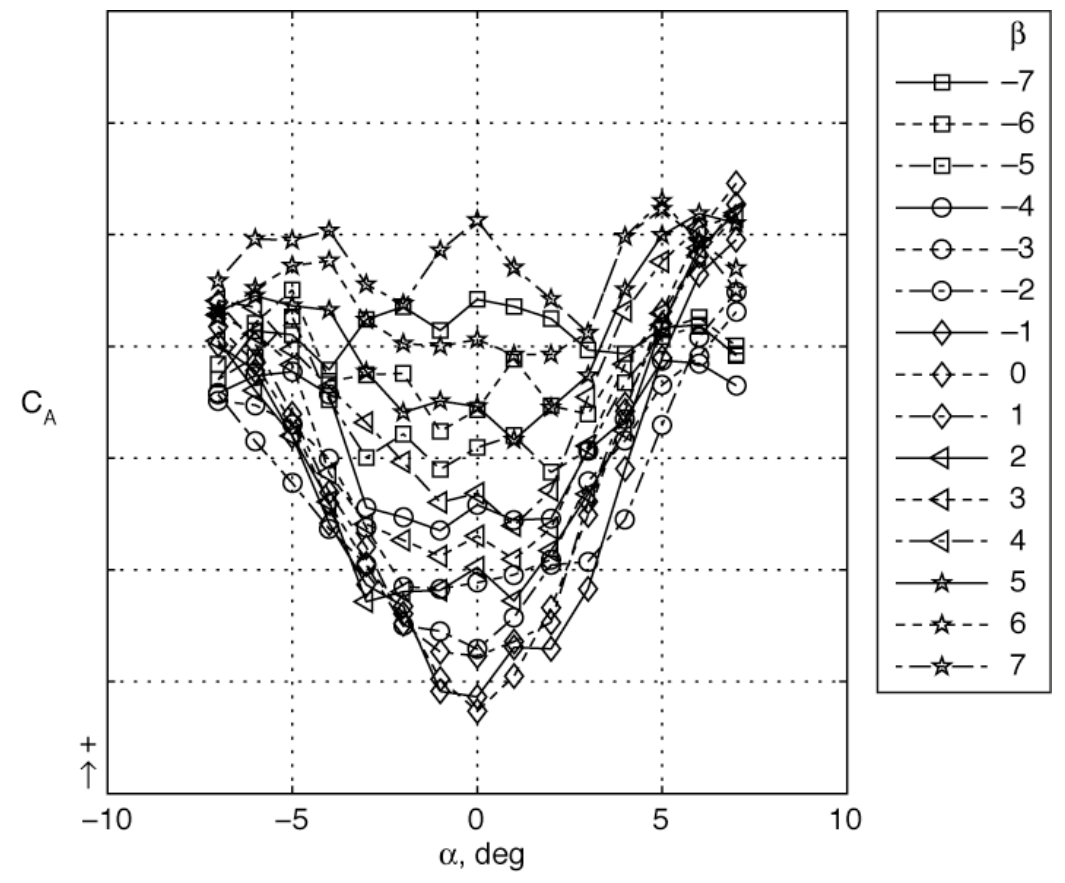

Figure 24. Axial force coefficient at Mach $=0.5$ (ascent database).

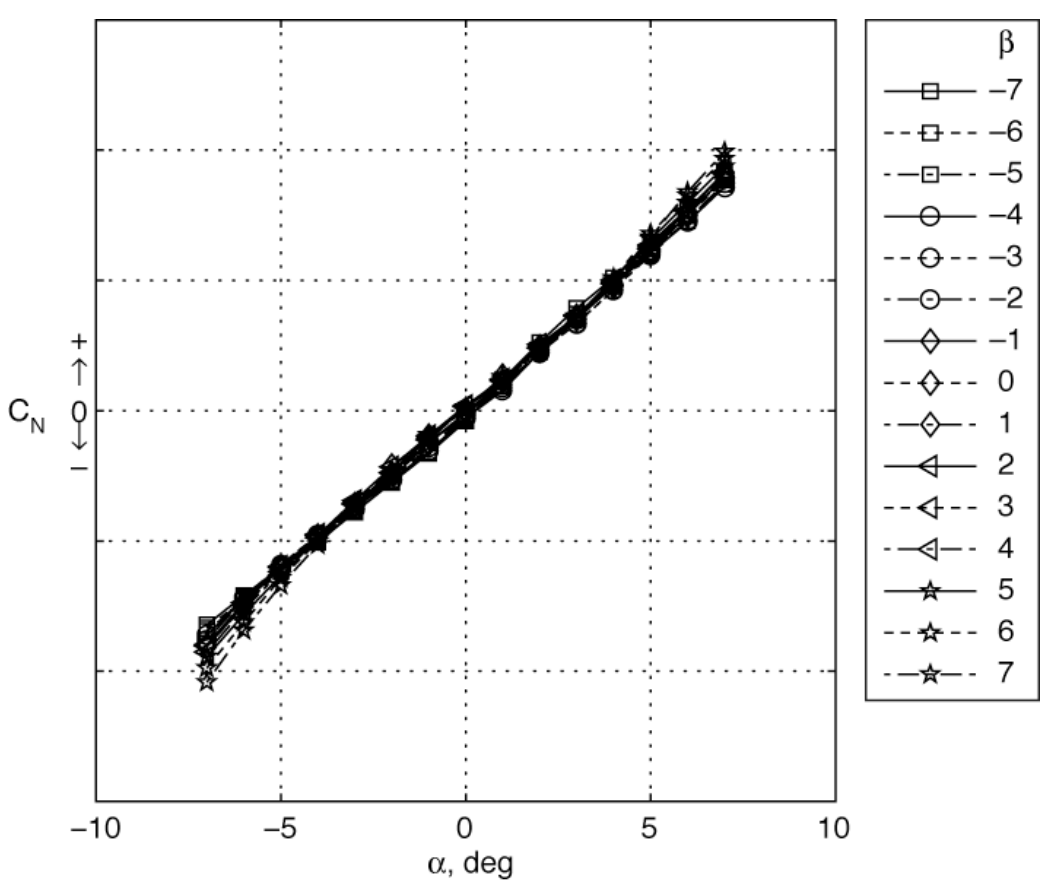

Figure 25. Normal force coefficient at Mach $=\mathbf{0 . 5}$ (ascent database). 


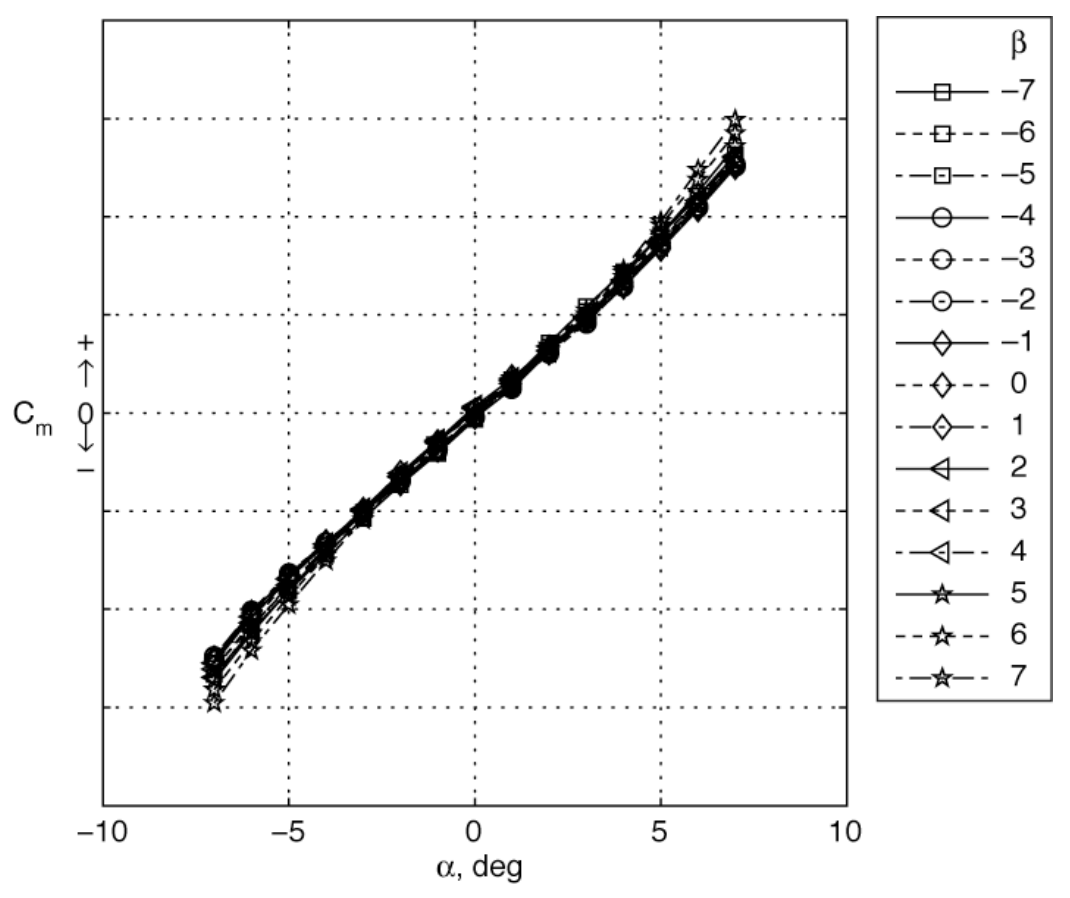

Figure 26. Pitching moment coefficient at $\mathrm{Mach}=0.5$ (ascent database).

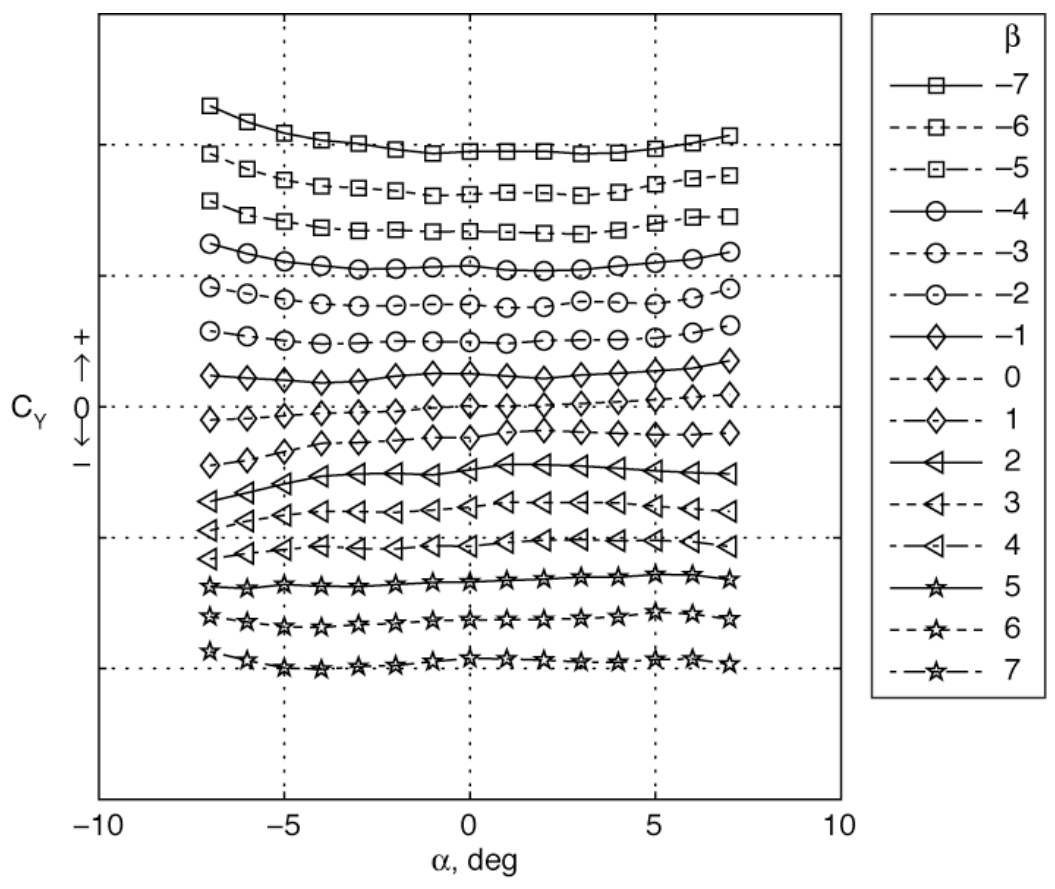

Figure 27: Side force coefficient at Mach $=0.5$ (ascent database).

19

American Institute of Aeronautics and Astronautics 


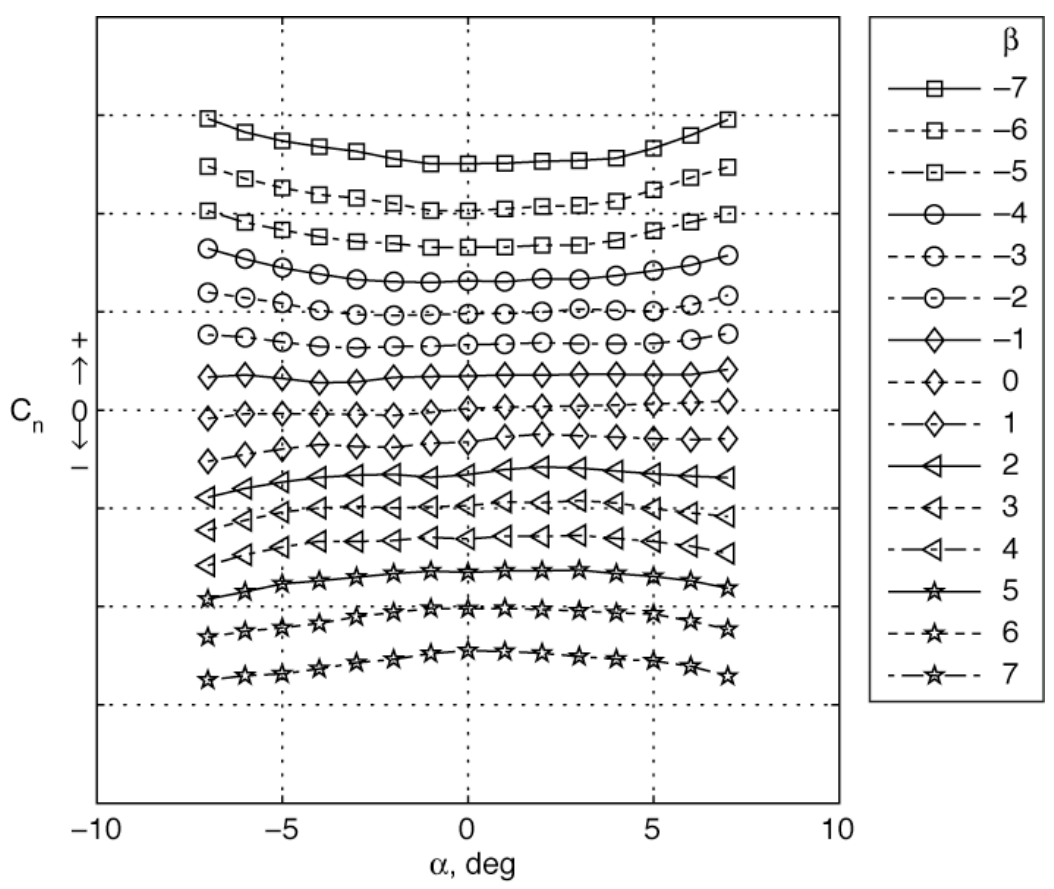

Figure 28. Yawing moment coefficient at Mach $=0.5$ (ascent database).

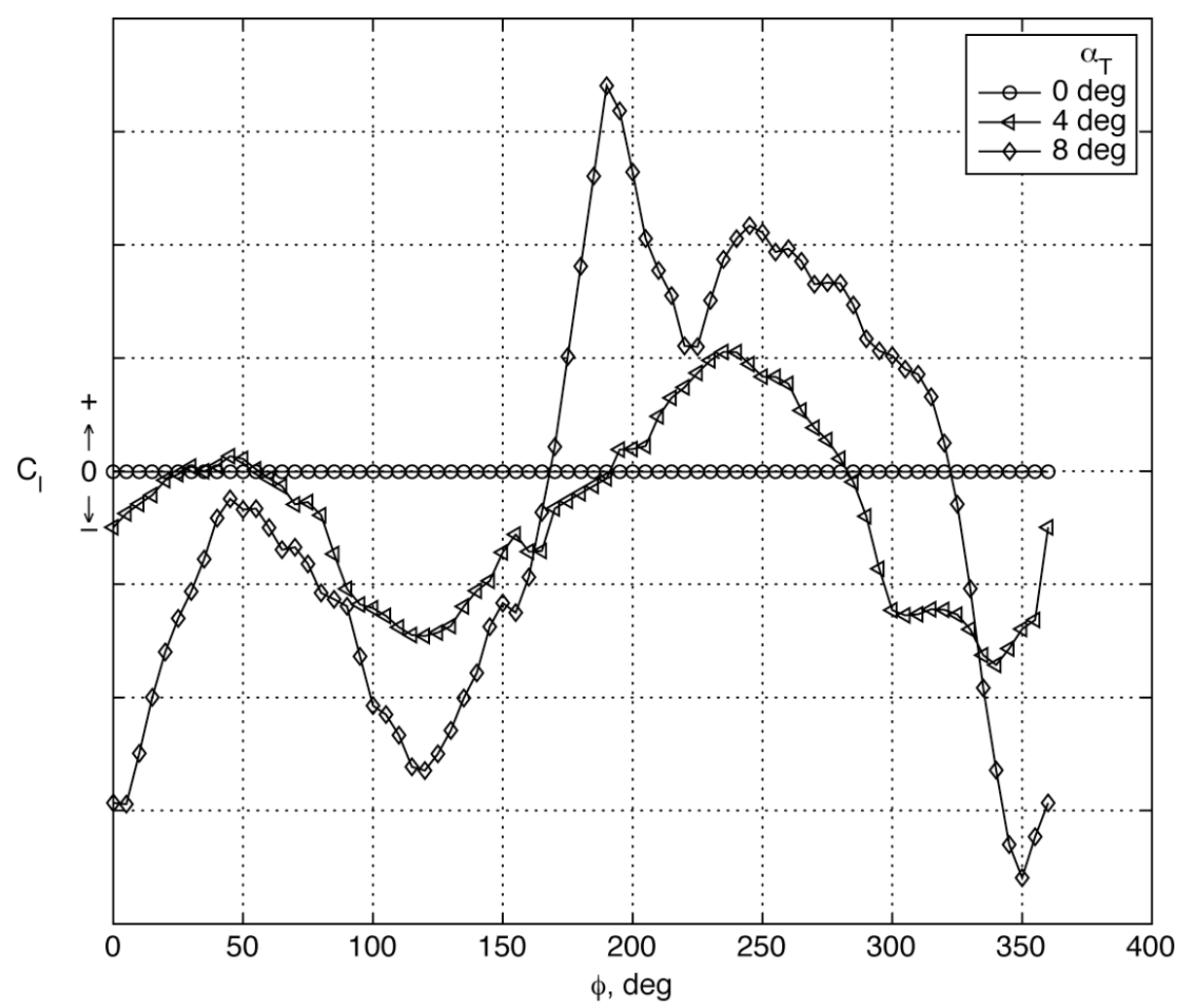

Figure 29. Rolling moment coefficient at $\mathrm{Mach}=0.5$ (ascent database).

American Institute of Aeronautics and Astronautics 

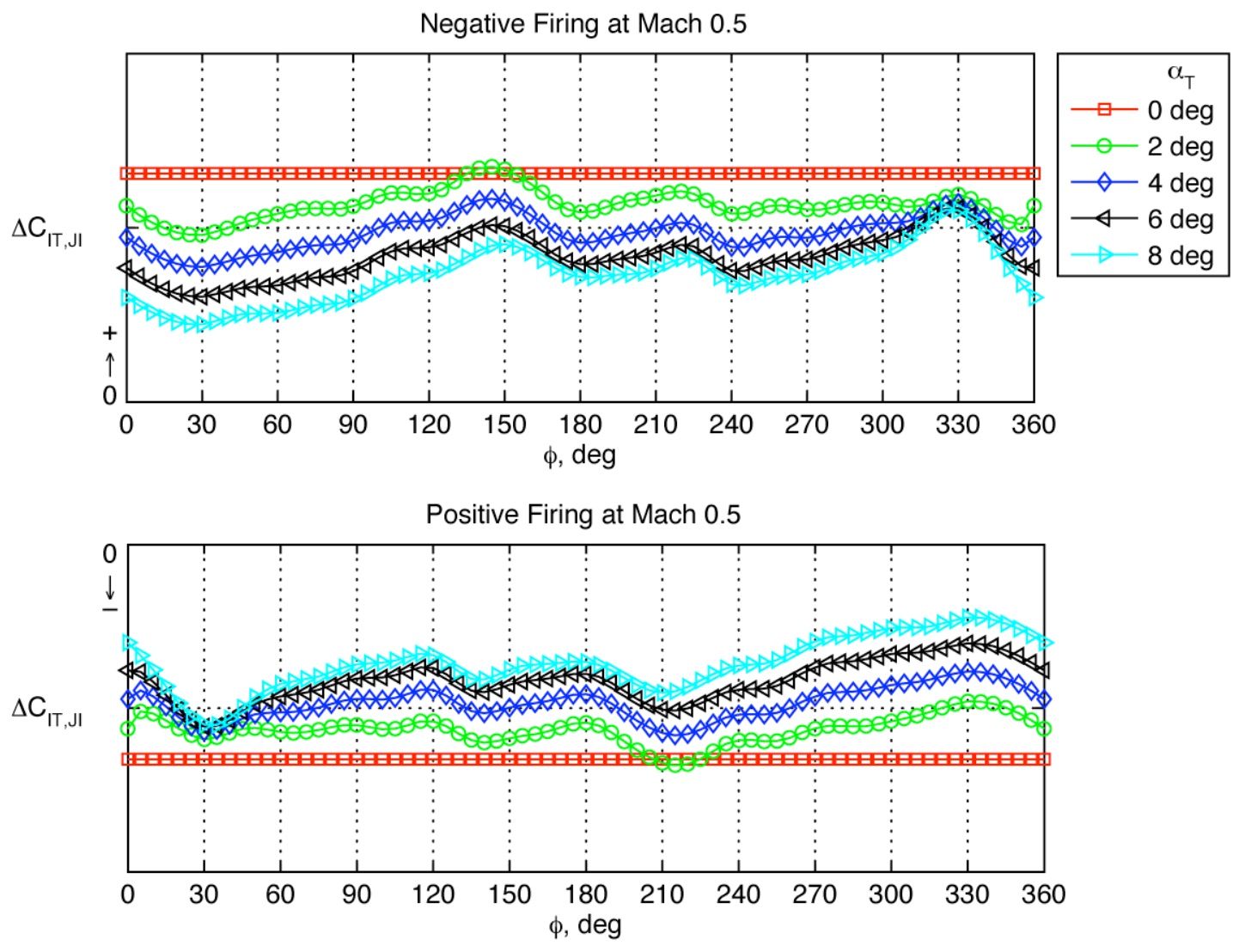

Figure 30. RoCS JI rolling moment incremental coefficients at Mach $=0.5$.

A sample result for RoCS JI rolling moment incremental coefficient is presented in Figure 30 for Mach 0.5. The increments are largest in magnitude at $\alpha_{\mathrm{T}}=0$ and decrease as $\alpha_{\mathrm{T}}$ increases. For negative firing case, the rolling moment incremental coefficients are positive which implies that the aerodynamic jet interaction produces adverse effect leading to a loss of RoCS thruster effectiveness and vice versa for positive firing case.

\section{Concluding Remarks}

Aerodynamic analyses and database development of the A106 lift-off/transition, ascent, and jet induced aerodynamic effects due to RoCS thruster firing are presented in this paper. High fidelity lift-off/transition database with minimal empirical estimates was needed for Ares I crew launch vehicle because preliminary simulations had indicated a potential for impact of the vehicle with the tower. To meet this requirement, the lift-off/transition database was developed using NASA Langley 14x22 SWT test data on 1.75\% A106 scale model. During ascent, the roll control system designed to balance combined RSRMV roll torque and aerodynamic rolling moment is pushed to its limits especially in regions of high dynamic pressure. Therefore, it was necessary to accurately characterize the aerodynamic coefficients, particularly the rolling moment coefficient during first stage ascent. To meet this requirement, the power-off ascent database was developed using test data from Boeing PSWT and NASA Langley UPWT tunnels on 1\% A106 scale model using specially designed strain gage balances. Further, an adjustment for Reynolds number differences between wind tunnel and flight conditions was made using OVERFLOW and USM3D CFD solutions. However, no Reynolds number adjustment was made to lift-off/transition database because it was believed that fullscale flow conditions were simulated on the test model with uniform grit. The RoCS jet interaction effects were modeled using CFD solutions at flight Reynolds numbers. Estimation of uncertainty was not discussed in this paper. Additional details on database development, uncertainty development and database implementation are available in A106 aerodynamic data book 5 . 


\section{Acknowledgment}

Dr. Khaled S. Abdol-Hamid, Dr. Robert M. Hall, Dr. Michael J. Hemsch, John W. Paulson, Jr, Dr. Scott D. Holland, Dr. John W. Van Norman, and William G. Tomek are acknowledged for help and assistance throughout the course of this activity.

\section{References}

${ }^{1}$ Huebner, L. D., Haynes, D. A., Taylor, T. L., Hall, R. M., Pamadi, B.N., and Seaford, M. C.: "Status, Plans, and Initial Results for Ares I Crew Launch Vehicle Aerodynamics," Journal of British Interplanetary Society (UK), Vol. 61, 2008.

${ }^{2}$ Pamadi, B. N., Pei, J., Klopfer, G. H., Holland, S.D., and Covell, P.F.: “Aerodynamic Analyses and Database Development for Ares I Vehicle First Stage Separation,” 49th AIAA Aerospace Sciences Meeting, Orlando, FL, January 2011.

${ }^{3}$ Nunley, B.W., "Static Aerodynamic Characteristics of the Apollo-Saturn IB Vehicle," NASA TM X-53657, September 25, 1967.

${ }^{4}$ Operational Aerodynamic Data Book. STS85-0118-1 REV A, September 2008.

${ }^{5}$ Constellation Program Ares I Aerodynamic Data Book. CxP 72214, December 2010.

${ }^{6}$ Capone, F. J., Paulson, J. W., Jr., and Erickson, G. E.: Liftoff and Transition Aerodynamics of the Ares I (A106) Launch Vehicle. NASA Ares-AD-TA-0019, April 15, 2010.

${ }^{7}$ Abdol-Hamid, K. S., Ghaffari, F. and Parlette, E. B. "An Overview of Ares-I CFD Ascent Aerodynamic Data Development And Analysis Based on USM3D," 49th AIAA Aerospace Sciences Meeting, Orlando, FL, January 4-7, 2011.

${ }^{8}$ R. H. Nichols, R. W. Tramel, and P. G. Buning, "Solver and Turbulence Model Upgrades to OVERFLOW 2 for Unsteady and High-Speed Applications," AIAA-2006-2824, AIAA 36th Fluid Dynamics Conference, San Francisco, CA, June 2006.

${ }^{9}$ Pao, S., Deere, K., Abdol-Hamid, K. "Establishing Approaches to Modeling the Ares I-X and Ares I Roll Control system with Free-stream Interaction”, 49th AIAA Aerospace Sciences Meeting, Orlando, FL, January 4-7, 2011. 